University of Wollongong

Research Online

Faculty of Engineering and Information

Faculty of Engineering and Information

Sciences - Papers: Part A

Sciences

$1-1-2017$

\title{
Micromechanics-based investigation of fouled ballast using large-scale triaxial tests and discrete element modeling
}

Ngoc Trung Ngo

University of Wollongong, trung@uow.edu.au

Buddhima Indraratna

University of Wollongong, indra@uow.edu.au

Cholachat Rujikiatkamjorn

University of Wollongong, cholacha@uow.edu.au

Follow this and additional works at: https://ro.uow.edu.au/eispapers

Part of the Engineering Commons, and the Science and Technology Studies Commons

Research Online is the open access institutional repository for the University of Wollongong. For further information contact the UOW Library: research-pubs@uow.edu.au 


\title{
Micromechanics-based investigation of fouled ballast using large-scale triaxial tests and discrete element modeling
}

\begin{abstract}
Railway ballast comprises unbounded discrete grains that are often used to form a load-bearing platform for tracks. Ballast degradation as trains pass over the tracks and infiltration of external fines including slurried (pumped) fine subgrade soils are two of the main reasons for ballast fouling. Fouling causes tracks to settle and also reduces the load-bearing capacity, which is associated with a reduction in internal friction and increased lateral spreading of the ballast layer. This paper presents a study of mobilized friction angle, volumetric behavior, and associated evolutions of contact and fabric anisotropy of fouled ballast subjected to monotonic triaxial loading using a series of large-scale triaxial tests and discrete element modeling. Monotonically loaded and drained triaxial tests were carried out on ballast with levels of clay fouling that varied from 10 to $50 \%$ void contamination index (VCl) subjected to three confining pressures of 10,30 , and $60 \mathrm{kPa}$. The results showed that an increase in the level of fouling decreased the mobilized friction angle and increased the ballast dilation. The discrete element method (DEM) was used to study the mobilized friction angle and fabric anisotropy of fresh and fouled ballast by simulating actual large-scale triaxial tests. Irregular shaped grains of ballast were simulated by clumping bonded circular balls with appropriate sizes and positions together. Ballast fouling was approximately simulated in DEM by adding 1-mm particles into the pore spaces of the fresh ballast. The predicted mobilized friction angles and volumetric changes obtained from the DEM simulations agreed well with those measured in the laboratory, indicating that the peak friction angle of fouled ballast and dilation decreased as the degree of fouling increased. The DEM simulations provided an insight into the distribution of contact force chains, contact orientations, and evolution of fabric anisotropy of fresh and fouled ballast that could not be captured in the laboratory. These observations are important for a better understanding of the load-deformation behavior of fouled ballast from the perspective of micromechanics.
\end{abstract}

\section{Keywords}

element, discrete, tests, triaxial, modeling, scale, fouled, large, ballast, micromechanics, investigation

Disciplines

Engineering | Science and Technology Studies

\section{Publication Details}

Ngo, N., Indraratna, B. \& Rujikiatkamjorn, C. (2017). Micromechanics-based investigation of fouled ballast using large-scale triaxial tests and discrete element modeling. Journal of Geotechnical and Geoenvironmental Engineering, 143 (2), 04016089-1-04016089-16. 


\section{Micromechanics based investigation of fouled ballast using large-scale triaxial tests and discrete element modelling}

Ngoc Trung Ngo, PhD, MEng, BEng

Lecturer, School of Civil, Mining and Environmental Engineering, University of Wollongong, Wollongong City, NSW 2522, Australia; ARC Centre for Excellence for Geotechnical Science and Engineering, Australia

Buddhima Indraratna, PhD (Alberta), FIEAust.,FTSE, FASCE

Research Director, Distinguished Professor of Civil Engineering, Centre for Geomechanics and Railway Engineering, Faculty of Engineering, University of Wollongong, Wollongong, NSW 2522, Australia. ARC Centre for Excellence for Geotechnical Science and Engineering, Australia

University of Wollongong, PhD, MEng, BEng

Associate Professor, Centre for Geomechanics and Railway Engineering, Faculty of Engineering, University of Wollongong, Wollongong City, NSW 2522, Australia; ARC Centre for Excellence for Geotechnical Science and Engineering, Australia

Technical paper submitted to: Journal of Geotechnical and Geoenvironmental Engineering ASCE

Author for correspondence:

Distinguished Professor Buddhima Indraratna

Faculty of Engineering

University of Wollongong

Wollongong, NSW 2522

Australia.

Ph: +612 42213046

Fax: +61 242213238

Email: indra@uow.edu.au 


\title{
Micromechanics based investigation of fouled ballast using large-scale triaxial tests and discrete element modelling
}

\author{
Ngoc Trung Ngo ${ }^{1}$, Buddhima Indraratna ${ }^{2}$, and Cholachat Rujikiatkamjorn ${ }^{3}$ \\ ${ }^{1}$ Lecturer, School of Civil, Mining and Environmental Engineering, Faculty of Engineering and Information Sciences, University of \\ Wollongong, Wollongong City, NSW 2522, Australia; ARC Centre for Excellence for Geotechnical Science and Engineering, Australia. \\ Email: trung@uow.edu.au, Ph: +61 242214892 Fax: +61 242213238 \\ ${ }^{2}$ Research Director, Distinguished Professor of Civil Engineering, Centre for Geomechanics and Railway Engineering, Faculty of \\ Engineering and Information Sciences, ARC Centre of Excellence for Geotechnical Science and Engineering, University of Wollongong, \\ Wollongong, NSW 2522, Australia. Email: indra@uow.edu.au, Ph: +61 242213046 Fax: +61 242213238 \\ ${ }^{3}$ Associate Professor, Centre for Geomechanics and Railway Engineering, Faculty of Engineering and Information Sciences, ARC Centre of \\ Excellence for Geotechnical Science and Engineering, University of Wollongong, Wollongong, NSW 2522, Australia. Email: \\ cholacha@uow.edu.au, Ph: +61 242215852 Fax: +61 242213238
}

\section{ABSTRACT}

Railway ballast comprises unbounded discrete grains that are often used to form a loadbearing platform for tracks. Ballast degradation as trains pass over the tracks and infiltration of external fines including slurried (pumped) fine subgrade soils, are two of the main reasons for ballast fouling. Fouling causes tracks to settle and also reduces the load bearing capacity that is associated with a reduction in internal friction and increased lateral spreading of the ballast layer. This paper presents a study of mobilised friction angle, volumetric behaviour and associated evolutions of contact and fabric anisotropy of fouled ballast subjected to monotonic triaxial loading using a series of large-scale triaxial tests and discrete element modelling. Monotonically loaded and drained triaxial tests were carried out on ballast with levels of clay fouling that varied from $10 \%$ to $50 \%$ Void Contamination Index (VCI) subjected to three confining pressures of 10,30 and $60 \mathrm{kPa}$. The results showed that an increase in the level of fouling decreased the mobilised friction angle and increased the ballast dilation. The discrete element method (DEM) was used to study the mobilised friction angle and fabric anisotropy of fresh and fouled ballast by simulating actual large-scale 
triaxial tests. Irregular shaped grains of ballast were simulated by clumping bonded circular balls with appropriate sizes and positions together. Ballast fouling was approximately simulated in DEM by adding $1 \mathrm{~mm}$ particles into the pore spaces of the fresh ballast. The predicted mobilised friction angles and volumetric changes obtained from the DEM simulations agreed well with those measured in the laboratory, indicating that the peak friction angle of fouled ballast and dilation decreased as the degree of fouling increased. The DEM simulations provided an insight into the distribution of contact force chains, contact orientations, and evolution of fabric anisotropy of fresh and fouled ballast that could not be captured in the laboratory. These observations are important for a better understanding of the load-deformation behaviour of fouled ballast from the perspective of micromechanics.

\section{Introduction}

Railways provide an efficient and economic mode of transport in many countries worldwide.

A ballast layer is an essential component of the rail track that is used as a load bearing platform and is responsible for maintaining track alignment (Selig and Waters 1994). Ballast commonly consists of medium to coarse-sized aggregates whose main purposes are to: (i) distribute the train load to the underlying layers at a reduced stress level; (ii) provide sufficient lateral confinement to the track, and (iii) provide a free draining condition. Under train operations the ballast progressively deteriorates and becomes fouled, which decreases its shear strength (Lackenby et al. 2007; Huang and Tutumluer 2011; Indraratna et al. 2013a). Ballast fouling is one of the major causes of substructure deterioration. Sources of fouling can be attributed to the breakage of angular corners and sharp edges, infiltration of fine particles, or clay pumping from underlying layers subjected to high cyclic load and saturated subgrade conditions (Selig and Waters 1994; Suiker et al. 2005; Anderson and Fair 2008; Indraratna et al. 2011a). Given that trains usually operate in low-lying coastal regions in 
Australia where the subgrades are commonly saturated, the fines (mud, clays and silt-size particles) of the subgrade tend to be pumped up into the ballast layer as slurry under cyclic train loading (Trani and Indraratna 2010; Indraratna et al. 2013b). When track substructures do not have a proper filter layer, the pumping of subgrade clay becomes more severe and is a main source of ballast fouling (Indraratna et al. 2011a). It is noted that the degree of saturation can certainly influence the possibility of clay pumping. Under this condition, significant excess pore water pressure can be generated under fast moving trains (i.e., high cyclic loading), thereby reducing the track resiliency and stability apart from enhanced clay pumping (Ni et al. 2014). In cases where the entrapment of fines into the ballast aggregates becomes significant, this would reduce the drainage capacity of the tracks, increase the excessive pore water pressure and thus decrease the effective bearing capacity of the track (Budiono et al. 2004; Tutumluer et al. 2008; Indraratna et al. 2011a).

Although severe problems associated with ballast fouling have been documented, only a limited amount of research has been carried out to study the mobilised friction angle and dilation of fouled ballast. Budiono et al. (2004) and Tutumluer et al. (2008) stated that fine particles decreased the stiffness of track substructure and when the degree of fine particles becomes excessive, it can govern the strength of the ballast and ultimately cause the track to become unstable. Dombrow et al. (2009) and Ebrahimi et al. (2014) carried out large-scale tests of fouled ballast and reported that as the level of fouling increased the shear strength steadily decreased. This reduction in the shear strength of fouled ballast associated with coal and clay fouling was also observed in the laboratory by Indraratna et al. (2011b) and Indraratna et al. (2013b).

The discrete element method (DEM) proposed by Cundall and Strack (1979) has been widely used to examine the micromechanical properties of ballast materials (Lim and McDowell 
2005; Lobo-Guerrero and Vallejo 2005; Tutumluer et al. 2007; Bhandari et al. 2009; O'sullivan and Cui 2009; Lobo-Guerrero and Vallejo 2010; Lu and McDowell 2010; Zhang et al. 2013; Huang et al. 2013; Tutumluer et al. 2013; Mishra et al. 2014; Indraratna et al. 2015; Ngo et al. 2015; Qian et al. 2015), among others, but most of these numerical studies focused on fresh ballast. McDowell et al. (2006) used the discrete element method to model largescale triaxial experiments of ballast aggregates reinforced with geogrids, and concluded that the DEM approach holds much promise as a tool for investigating granular aggregate assemblies. Bolton et al. (2008) used the DEM to simulate triaxial compression shearing tests for both breakable and unbreakable agglomerate assemblies, capturing the influence of confining pressure on the stress-strain and volumetric response. Lu and McDowell (2008) studied the stress-strain response of ballast subjected to monotonic loading using the DEM. The results indicated that particle shape, inter-particle friction, interlocking and asperity fracture all govern the mechanical behaviour of railway ballast. The use of DEM for predicting the mobilised friction angle of fouled ballast has been very limited in literature. Huang and Tutumluer (2011) used DEM to simulate fouled ballast under direct shear test conditions and reported that fouling is a critical agent that could affect particle interaction and cause the track to become distressed. Indraratna et al. (2014) used DEM to model direct shear tests for coal-fouled ballast and showed that coal fines would reduce the shear strength of fouled ballast. They observed that miniature particles (i.e. fouling materials) filled the voids between the ballast particles and coated their surfaces, this reduced inter-particle friction and the overall shear strength of the fouled-ballast assembly. Although these studies indicated that the influence of fouling materials on the shear stress-strain behaviour of ballast could be captured by DEM, they did not examine the micromechanical aspects of fouled ballast in detail where the spatial distribution of contact forces and evolutions of fabric anisotropy could play decisive roles in the stress-strain and dilation responses of fouled ballast. Ouadfel 
and Rothenburg (2001) first introduced a stress-force-fabric relationship for ellipsoids in three dimensions where numerical simulations were carried out with assemblies of ellipsoidal particles to verify the proposed theoretical model. It is noted that ellipsoidal particles were 'grown' from a dense assembly of equal size spheres by changing the particle aspect ratio, while maintaining a constant volume. On the contrary, the current DEM analysis uses irregularly-shaped particles (i.e. clumps) by connecting a number of particles together in appropriate sizes and positons. It also represents the actual particle size distribution of ballast aggregates, while considering the effects of fines retained in the voids and lubricating the grain surfaces.

This paper presents an attempt to apply DEM to model fouled ballast by capturing the mobilised friction angles and volumetric behaviour as well as the micromechanical characteristics of fouled ballast subjected to monotonic triaxial loading.

\section{Experimental study}

\section{Large-scale triaxial test}

The large-scale triaxial apparatus used in this study was designed and built at the University of Wollongong specifically for testing ballast aggregates (Indraratna et al. 1998). It can accommodate a sample of ballast $600 \mathrm{~mm}$ high by $300 \mathrm{~mm}$ in diameter, and consists of a dynamic actuator capable of applying deviatoric stresses of up 2.1 MPa and a maximum load frequency of $60 \mathrm{~Hz}$. The apparatus was instrumented with pressures cells and linear variable differential transducers to monitor the stresses and corresponding strains at regular intervals during testing. Ballast used in this study is latite basalt of volcanic origin, commonly used in Australian tracks in the state of New South Wales. It was cleaned, dried, and sieved according to the current Australian Standard AS2758.7 (1996). Clay was used as a fouling 
material in this study. The particle size distribution, unit weight of the ballast and clay were kept almost identical in all tests to represent actual materials in the track, as shown in Figure 1a. Fouled particles were mixed with the ballast aggregates during the sample preparation and it was also visibly inspected after the tests. Photos of ballast mixed with kaolin and fouled ballast at VCI $=50 \%$ is shown in Figures $1 \mathrm{~b}$-c. The mechanical properties of the ballast and clay tested in the study are also presented in Table 1 . To quantify levels of ballast fouling, the void contaminant index (VCI) that considers the specific gravity of the fouled material, as proposed earlier by (Tennakoon et al. 2012), was adopted and is given by:

$V C I=\frac{1+e_{f}}{e_{b}} \times \frac{G_{s b}}{G_{s f}} \times \frac{M_{f}}{M_{b}} \times 100$

where $e_{f}=$ void ratio of fouling material, $e_{b}=$ the void ratio of fresh ballast, $G_{s b}=$ the specific gravity of ballast, $G_{s f}=$ the specific gravity of fouling material, $M_{f}=$ the dry mass of fouling material, $M_{b}=$ the dry mass of fresh ballast.

A series of fully drained triaxial tests for fresh and clay-fouled ballast were conducted at a sufficiently low axial strain rate of $0.55 \mathrm{~mm} / \mathrm{min}$, which allowed excess pore pressure to dissipate completely under this monotonic loading condition. To create a sample of fouled ballast at a specified VCI, a predetermined amount of fouling material (e.g. etermined from Equation 1) was mixed with ballast aggregates inside a concrete mixer to ensure test specimens were consistent. The fouled ballast was then placed inside the chamber and compacted to a unit weight of $14.3 \mathrm{kN} / \mathrm{m}^{3}$ for every $150 \mathrm{~mm}$-thick layer until a final height of $600 \mathrm{~mm}$ was reached. Once the sample preparation was completed, the specimen was saturated from bottom to top, where a back pressure in the vicinity of $80 \mathrm{kPa}$ was applied to ensure saturation with Skempton's B value approaching unity (B>0.98). Depending on the level of clay fouling, the saturation could take up to several hours, whereas for fresh ballast 
the value of B approached 0.99 within a few minutes. Based on visual inspection, fouling material coating the entire surface area of ballast was observed during and after the saturation process, and also the clay particles did not flow to the same part of the specimen during the process of saturation even when the VCI was low. Large-scale triaxial tests were carried out at various levels of fouling, ranging from $\mathrm{VCI}=10 \%$ to $\mathrm{VCI}=50 \%$, and subjected to three confining pressures of $10 \mathrm{kPa}, 30 \mathrm{kPa}$, and $60 \mathrm{kPa}$. The confining pressure selected for the current study was determined using field measurements of typical Australian tracks by Indraratna et al. (2010) who indicated that the lateral confining pressure provided by the sleepers, shoulder and crib ballast rarely exceeded $60 \mathrm{kPa}$. Typical heavy haul trains of 20-30 tonne axle loads indicate confining pressures in the range of 10 to $40 \mathrm{kPa}$, while tracks prepared for 40 tonne axle loads indicate confining pressures up to $60 \mathrm{kPa}$, as obtained from field data. Every test was conducted to an axial strain $\left(\varepsilon_{a}\right)$ of $28 \%$ (i.e. the maximum movement allowed by the triaxial apparatus), during which the stress-strain response and volumetric change were recorded. The detailed results and analysis are presented elsewhere by Indraratna et al. (2013a) and they highlighted that the peak deviatoric stress $\left(q=\sigma_{1}^{\prime}-\sigma_{3}^{\prime}\right)$ and the corresponding initial deformation modulus increased with an increase in the confining pressure at a given level of fouling. Mobilised friction angles $(\phi)$ of the fresh and fouled ballast under different confining pressures measured in laboratory are presented in Figure 2a. It is seen that when the level of fouling increases, the mobilised friction angle decreases markedly because fouled particles fill the voids of the ballast aggregates, coat their surfaces which decreases the interparticle friction and the shearing resistance of the ballast assembly. It is noted that both the fouled particles filling the voids and fouled particles coating ballast surface cause the shearing resistance to decrease. Indeed, both these actions contribute to decreased particle interlock while facilitating ballast aggregates to roll and slide over each other, which in turns decreases the shearing resistance. Given the scope of the 
current study, any stabilisation effect of the fines when VCI $>40 \%$ was not considered, as rail tracks in Australia are subjected to maintenance before an excessive level of VCI is reached. The volumetric strains of this ballast at varying levels of fouling and confining pressures are also presented in Figure 2a, which indicates that an increase in the confining pressure results in a decrease in the rate and magnitude of dilation. Compared to fresh ballast (VCI $=0 \%$ ), at an increased level of fouling the ballast medium shows a general decrease in dilation, and this is indicated in Figure $2 \mathrm{~b}$ representing the variation of dilation angle with VCI. It is seen that when the degree of fouling less than $40 \%$, the average dilation angle decreases as the VCI increases for a given confining pressure. When the VCI exceeds $40 \%$, the corresponding dilation angle remains relatively unchanged. Indeed, the fouling of ballast by clay causes a reduction in shear strength and decrease the corresponding dilation, as measured in the laboratory. On the basis of numerous track performance assessments, VCI $=40 \%$ is mainly an engineering judgment or practice guide, and not a stringent criterion for dilation behaviour. When VCI is greater than $40 \%$, ballast exhibits significant deformation, and track maintenance is usually undertaken before this level is reached, as discussed by Indraratna et al. (2013). Figure 2c shows the variation of apparent peak friction angles $\left(\phi_{p}^{\prime}\right)$ of fouled ballast with VCI at a given confining pressure. The peak friction angle is observed to decrease rapidly as the clay fouling increases, particularly within the range of VCI=10\%$40 \%$. The fouling materials inhibit the full mobilisation of the inter-particle friction as they coat the aggregate surfaces (lubrication effect), thereby reducing the shear strength of the ballast assembly. Indraratna et al. (2013a) observed that at a very high confining pressure (i.e. $\sigma_{3}^{\prime}>200 \mathrm{kPa}$ ), irrespective of the level of fouling the apparent peak friction angle converged approximately to a value of around $30^{\circ}$. This observation implies that the plastic clay is supressed as the coarse ballast grains are forced into making contact regardless of the pore spaces being filled with the fouled material. 


\section{Discrete Element Modelling}

The discrete element method (DEM) was used in this study to investigate the shear stressstrain behaviour of clay-fouled ballast. DEM has been often used to model ballast because it can capture the discrete nature of particulate materials (Oda and Iwashita 1999; O'sullivan 2011). DEM can examine the mechanical behaviour of a granular assembly consisting of a collection of arbitrarily shaped discrete particles subjected to quasi-static and dynamic conditions (Lu and McDowell 2008; O'sullivan and Cui 2009; Tutumluer et al. 2012). In DEM, the force-displacement law derives the contact force acting on two particles in contact to the relative displacement between them (Itasca 2014). At a given time, the force vector $\overrightarrow{\boldsymbol{F}}$ that represents the interaction between the two particles (Figure 3a) is resolved into normal $\left(\overrightarrow{\boldsymbol{F}}_{N}\right)$ and shear component $\left(\overrightarrow{\boldsymbol{F}}_{T}\right)$ with respect to the contact plane:

$\overrightarrow{\boldsymbol{F}}_{N}=K_{N} U^{n}$

$\delta \overrightarrow{\boldsymbol{F}}_{T}=-K_{T} \cdot \delta U^{S}$

where, $K_{N}$ and $K_{T}$ are the normal and shear stiffnesses at the contact; $U^{n}$ is the normal contact displacement (Figure 3a); $\delta U^{s}$ is the incremental shear displacement; and $\delta \overrightarrow{\boldsymbol{F}}_{T}$ is the incremental shear force. The new shear contact force is determined by summing the old shear force existing at the start of the time-step with the shear elastic force increment

$\overrightarrow{\boldsymbol{F}}_{T} \leftarrow \overrightarrow{\boldsymbol{F}}_{T}+\delta \overrightarrow{\boldsymbol{F}}_{T} \leq \mu \overrightarrow{\boldsymbol{F}}_{N}$

where, $\mu$ is the friction coefficient. 


\section{Modelling the triaxial test in DEM}

Figure 4 shows a DEM model of a large-scale triaxial test $(600 \mathrm{~mm}$ high by $300 \mathrm{~mm}$ in diameter). These dimensions are identical to those carried out in the laboratory by Indraratna et al. (2013a). A top wall platen was forced to move downwards to apply a required deviatoric stress while the vertical walls were moved inwards or outwards by a servo to maintain the required confining pressure (Itasca 2014). Ballast grains with different shapes and sizes were simulated by connecting many spherical balls together at appropriate sizes and positions to resemble the actual ballast gradation conducted in the laboratory. A library of six ballast particles with sizes ranging from 13.2 to $53 \mathrm{~mm}$ was generated by connecting 25 to 40 spherical balls together for the current DEM analysis, as shown in Figure 5. The clumped particles has been adopted previously by Lim and McDowell (2005); Ferellec and McDowell (2008) to generate non-spherical particles. The typical particle shapes selected from real aggregates were mimicked by connecting a number of spherical balls at appropriate sizes and positions, as illustrated in Figure 5. A total of 15,234 particles were generated in the triaxial assembly. It took approximately 215 hours for simulating fresh ballast, whereas it required up to 634 hours for fouled ballast ( $\mathrm{VCI}=50 \%$ ) to attain $28 \%$ axial strain (running on a Workstation, Dell Precision T7500, 24GB- RAM). It is noted that a clump acts as a rigid body in which the internal contacts are ignored and the overlapping mass in clumps, which can be affected on particle rotations, is dealt with in this analysis by determining a corrected volume for each clump. The simulated ballast particles were placed at random locations without any overlapping within the specified cylindrical boundary and were then compacted to a bulk unit weight of $14.3 \mathrm{kN} / \mathrm{m}^{3}$ to represent the actual experimental and field conditions (Indraratna et al. 2013a). The initial specimen of simulated ballast was isotopically compressed to three different confining pressures $\left(\sigma_{3}^{\prime}=10,30\right.$, and $\left.60 \mathrm{kPa}\right)$. The assembly was then cycled to attain equilibrium where the ratio of the maximum unbalanced force to the 
mean contact force became smaller than a set tolerance value of $2.50 \times 10^{-4}$. It is noted that the damping ratio is an important parameter not only in soil dynamics but also in DEM simulation when the nonlinear contact model is used. Nevertheless, the current DEM analysis was limited to the linear contact model to reduce the computation time, and therefore the damping ratio was not required. The micromechanical parameters used in this study to model ballast were adopted from Indraratna et al. (2014) since the same ballast material was tested (i.e. latite basalt, collected from the Bombo quarry near the city of Wollongong). These parameters were chosen by calibrating the shear stress-strain response of ballast obtained from DEM simulations with those measured in the laboratory, as given in Table 3.

Monotonically loaded drained triaxial tests subjected to a specified confining pressure were performed where each simulation was sheared to an axial strain of $28 \%$. During loading, the displacement of the top plate and the surrounding walls were recorded to determine the axial and associated volumetric strains. Figure 6 presents comparisons of the mobilised friction angles and volumetric change of fresh ballast obtained from the DEM simulations and those measured experimentally while subjected to a confining pressure range of 10 to $60 \mathrm{kPa}$. It is seen in Figure 6 that the DEM predictions generally agree well with the experimental data and show that as the confining pressure increases the ballast experiences a decrease in the mobilised peak friction angle. Moreover, a sample subjected to low confining pressure $\left(\sigma_{3}^{\prime}=10 \mathrm{kPa}\right)$ experiences a greater dilation but a smaller initial compressive volumetric strain, unlike those samples subjected to a higher confinement. Some disparities in the volumetric change response are noted where the DEM simulations predict less compression than the laboratory measurements. This difference may be attributed to some particle degradation that could not be accurately captured in the DEM simulation and potentially to the rigidity of the loading plate and surrounding walls. This was also observed by Bolton (1986) that reduced peak strength and dilation as stress level increases was due to particle 
degradation. It is also noted that the difference between clumped DEM spheres and actual angularity of ballast aggregates can affect both the shear strength and corresponding volumetric change of ballast assembly. In the current DEM analysis, irrespective of the efforts made in the DEM to clump particles together (by connecting 25 to 40 spherical balls) to mimic physical corners of ballast aggregates (i.e. sharp, or angular), accurate representation of the actual physical corners of blasted and quarried aggregates and matching their surface roughness still remain an approximation in DEM albeit some improvements over the recent times. Dilation which depends on size and shape of particles will require further investigation for more accurate micro-mechanical modelling.

\section{Micromechanical analysis for ballast}

Load transfer in a granular assembly depends on the orientation of contacts where an applied load is transmitted to ballast grains through an interconnected network of force chains at contact points (Oda and Iwashita 1999). When subjected to shearing, a ballast assembly induces changes in the contact forces and subsequently changes the number of load-carrying contacts and their orientations. A fabric tensor is often used as an index to illustrate the packing structure of granular materials where the macroscopic stress-strain behaviour can be related to microscopic force and fabric parameters (i.e. stress-force-fabric relationship) as presented by Rothenburg (1980). Details of mathematical framework used to capture the evolution of fabric tensor in the current analysis were described by Ouadfel and Rothenburg (2001) and Chantawarangul (1993).

\section{Modelling fouling in the DEM}

It is imperative when using DEM is to determine appropriate micromechanical parameters that will result in a realistic macroscopic behaviour of a simulated material. Calibration was implemented in this study to determine the necessary parameters to model fouling by 
comparing the shear-strain response of fouled material obtained from DEM simulations and that measured in the laboratory using a series of direct shear tests for fouled material which were conducted according to the Standard D 3080 - 03 of ASTM (2003). The shear box was $60 \mathrm{~mm}$ long $\times 60 \mathrm{~mm}$ wide $\times 52 \mathrm{~mm}$ high, and was separated horizontally into two equal boxes. A series of simulated direct shear tests were then carried out in DEM to determine the appropriate micromechanical parameters for the fouled material. Experiment and DEM simulations were conducted under normal stresses of $25 \mathrm{kPa}$, and $40 \mathrm{kPa}$ up to a shear strain of $10 \%$. A DEM model of a direct shear test has identical dimensions with the shear box, where the fouled material was simulated approximately by uniform $1 \mathrm{~mm}$ spheres, as shown in Figure 7. It is known that fine particles (e.g. clay or coal particles) are very small and platelet-like shape in nature, and hence it is required extremely huge number of particles to simulate their actual size and shape. Given the friction angle and stiffness of the fine particles are very small compared to those for large ballast aggregates and computational calculation time required, the fouled particles are approximately modelled by $1 \mathrm{~mm}$ spheres in the current DEM analysis. To the Authors' knowledge, there have been limited DEM studies on fouling effects, and this study is an attempt to model fouled ballast using DEM with miniature particles trapped in the voids of large particles. The Authors acknowledge the limitations of this approach that flocculated clay particles are considerably smaller than $1 \mathrm{~mm}$ spherical particles, and that the effect of moisture and adhesion of fouling materials was not considered in the calibration process.

Several micromechanical parameters are needed to simulate a specific material in DEM, and it was found that friction coefficient $(\mu)$ and stiffness of particle contacts $\left(k_{n}, k_{s}\right)$ are generally considered as predominant parameters governing the stress-strain behaviour of the material (Oda and Iwashita 1999; O'sullivan 2011). To understand the significance of the friction coefficient $(\mu)$ on the stress-strain response of simulated fouling material, four 
simulations under direct shear conditions subjected to a normal stress of $25 \mathrm{kPa}$, where the values of $\mu$ varied from 0.15 to 0.5 while other parameters were kept constant (i.e. the contact normal and shear stiffness were set to $0.52 \times 10^{4} \mathrm{~N} / \mathrm{m}$ ) were conducted. Friction coefficient was selected within the range of $\mu=0.15-0.5$ for the purpose of DEM calibration and also as suggested in previous literature for various test conditions. The lower range values $(<0.25)$ is appropriate for clay-fouled ballast, while significantly higher values have been found for instance in coal-fouled ballast. Figure 8a shows the effects of the friction coefficient $(\mu)$ on the shear stress-strain behaviour, and indicates that at low shear strain $\left(\varepsilon_{s}<7 \%\right)$ an increase in friction coefficient resulted in an increase in the initial modulus of the assembly (i.e. the slope of the stress-strain curves), but, at a higher shear strain, the stress strain curves tended to converge together irrespective of the value of $\mu$. This observation is in agreement with the results reported by $\mathrm{Ni}$ et al. (2000) where they investigated the effects of the micromechanical properties of granular material on its shear stress-strain behaviour. Given the low friction coefficient of the fouling material and the use of $1 \mathrm{~mm}$ spheres to represent clay particles, a value of $\mu=0.25$ was found to best represent the stress-strain behaviour of the fouling material used in the laboratory. It is noted that Bhandari and Han (2010) used $\mu$ $=0.4$ to model soil-geotextile interaction, while Wang et al. (2007) used $\mu=0.5$ to model soils in direct shear box. The effects of the contact normal and shear stiffness $\left(k_{n}, k_{s}\right)$ were examined by performing other simulations under direct shear tests subjected to a normal stress of $40 \mathrm{kPa}$, while the other parameters remained unchanged (i.e. the friction coefficient $\mu$ was set to 0.25 ) as given in Table 2 . Figure $8 \mathrm{~b}$ presents comparisons of the shear stressstrain response obtained from the DEM simulations and those measured in the laboratory, and shows that the stress-strain response by Simulation 2 matched the experimental data reasonably well, indicating that the micromechanical parameters used in the simulation given in Table 3 for the fouled material were appropriate. The volumetric change was also captured 
by allowing a top loading plate to displace vertically. Positions of the top plate were monitor during the shearing process to determine the associated volume changes, as shown in Figure 8c. It is noted that spherical particles can roll and slide on each other in DEM, facilitating the specimens to compress as shown in Figure 8c. It is observed that the friction coefficient $(\mu)$ affected the initial stress-strain response, and hence the stiffness of the assembly, whereas an increase in the contact normal and shear stiffness $\left(k_{n}, k_{s}\right)$ led to increased peak shear strength. On the other hand, conducting a parametric study for $\mu$ helped to capture the stiffness and, by subsequently varying the stiffness $\left(k_{n}, k_{s}\right)$ allowed us to capture the peak shear stress (i.e shear strength) of the fine particles. Once the given set of micromechanical parameter was adequately calibrated with experimental data, they were then used to model the large-scale triaxial tests of clay-fouled ballast that is presented in the following sections.

\section{Modelling of fouled ballast in triaxial tests}

Ballast fouling is a result of fine particles that become contaminated in the voids of ballast, so ideally, fouled ballast can be modelled in DEM by placing a certain number of small particles into the voids. Huang and Tutumluer (2011) introduced a method to model fouled ballast in DEM by decreasing the inter-particle coefficient of friction of the ballast assembly. This approach is capable of modelling the shear stress-strain behaviour of fouled ballast within a reasonable computational time, but it could not capture the volumetric change (i.e. dilation) of ballast at different levels of fouling. In the current analysis, ballast fouling was modelled approximately by adding a pre-determined amount of $1 \mathrm{~mm}$ spheres in the voids between ballast to represent a given value of VCI (Tennakoon et al. 2012). It was expected that as the small particles filled the voids between the ballast that the inter-particle friction angle would decrease (Huang et al. 2009), where the reduction in the inter-particle friction angle was determined in the laboratory for different confining pressures, as shown in Figure 2c. The 
coefficient friction $(\mu)$ used to simulate fouled ballast in DEM at a given VCI was then determined so as to match the reduction in the apparent angle of friction of fouled ballast. The relevant micro-mechanical parameters $\left(k_{n}, k_{s}, \mu\right)$ used to model fouled ballast (VCI=25\% and 50\%) are shown in Tables 3 and 4, where an increase in VCI is represented by the increased number of particles added. Unlike some available studies where rolling resistance is explicitly considered (e.g. Jiang et al. 2005; Huang et al. 2013), the rolling of small spheres over large spheres is still captured indirectly in PFC3D (Particle Flow Code in 3D - ITASCA, 2014) by reducing the friction angle as a function of VCI. Jiang et al. (2005) included rolling resistance in their micromechanical model for granular media, with the rolling resistant moment related to the relative particle rotation and rotational stiffness. Recently, Huang et al. (2013) proposed a three-dimensional granular contact dynamics with rolling resistance where they incorporated some finite amount of rolling resistance into the basic sphere model. It is noted that rolling resistance is not explicitly included in PFC3D unlike some other DEM codes. However, in PFC3D volumetric strains including dilation can still be modelled by reducing the internal friction angle as a function of clay particle content (VCI) fouling the ballast (Indraratna et al. 2014).

\section{Results and Discussion}

\section{Mobilised friction angle and volumetric change analysis}

Due to the significant number of small particles and associated computational time required to simulate highly fouled ballast (VCI > 50\%), the current DEM analysis only considers for fouling levels of VCI=25\% and 50\%. Figure 9 shows the comparisons of mobilised friction angle and volumetric strain of fouled ballast between DEM simulations and experimental results. Here mobilised friction angle curves obtained from the DEM simulation are in good agreement with those measured in the laboratory. At a given confining pressure, the peak 
friction angle decreases with an increase in VCI because the small particles are expected to lubricate the surfaces of the rough ballast grains, thereby causing a reduction in the mobilised friction angle. These DEM simulations exhibit compression at the beginning of the test, followed by significant dilation. This is expected from dense granular materials that generally experience strain softening at high rates of dilation. In the dilation zone, where a specimen was highly fouled (VCI=50\%), it shows a decrease in the rate and magnitude of dilation at high axial strains $\left(\varepsilon_{a}>20 \%\right)$. This observation was supported by Indraratna et al. (2011b) when they demonstrated that fine particles would lubricate ballast aggregates and decrease the inter-particle friction angles, and thereby increase the plastic deformation and differential track settlement. The lubricating effect of fine particles (fouling material) coating the relatively rough surface of large aggregates can be attributed to the reduction of inter-particle friction and less interlocking of angular aggregates, causing a reduction in shear strength. There are some discrepancies in volumetric change between measured and predicted data, and this could be attributed to differences in particle angularity between the DEM simulation and the actual ballast aggregates tested.

Figure 10 shows the variations of deviatoric stress $(q)$ with the mean stress $(p)$ for fresh and fouled ballast (VCI=25\%, 50\%) obtained from DEM simulations and those measured in the laboratory. It is noted that all tests were conducted in an axial strain-controlled fashion where deviatoric stress, $q$ and mean stress, $p$ were obtained from axial stress $\left(\sigma_{1}\right)$ and confining pressure $\left(\sigma_{3}\right)$ as follows: $q=\sigma_{1}-\sigma_{3}$; and $p=\left(\sigma_{1}+2 \sigma_{3}\right) / 3$. The results show that an increase confining pressure usually results in an increase in the deviatoric stress as it requires a more than proportionately greater axial load to achieve the same level of axial strain. Conversely, for a given confining pressure the deviatoric stress decreases with an increase in VCI, as shown in Figures 10b-c, where a reduction in the shear strength of fouled ballast is basically associated with the presence of the fine particles. At the end of the triaxial tests, the 
states of stress $(p, q)$ of the fresh and fouled ballast that were subjected to different confining pressures could be approximated by a linear trend. In other words, irrespective of the confining pressures, the stress state of fresh and fouled ballast under triaxial shearing seems to move towards a unique (i.e. critical) state that is linearly related to each other in the $p, q$ plane. From the simulation results, it can be concluded that the DEM model can successfully capture the stress-strain response of fresh and fouled ballast. A detailed analysis of the micromacro response of fresh and fouled ballast is discussed below.

\section{Contact force orientations for fresh and fouled ballast}

The micromechanical analysis presented here focuses on the evolution of contact force distributions and orientations within the fresh and fouled ballast assembly. Rothenburg (1980) first introduced micro-mechanical analysis for idealised granular assemblies of disks (2D) and spheres (3D), and later on Chantawarangul (1993) extended the study for threedimensional granular assemblies. These studies have revealed that the anisotropic microstructure is mainly caused by the changes of particle contacts in the granular assembly.

In this study, the angularity of particles was simulated by clumping several spheres of different sizes together (i.e. not just narrowly graded spheres), and this would at least represent to some extent the fabric of the granular assembly, albeit limitations of any DEM analysis in the absence of exact angularity of each and every particle (a most cumbersome task if this has to be done in a granular assembly of thousands of dissimilar particles). The inclusion of small spheres would represent the fouling material, although we recognise within limitations, that the coefficient of contact anisotropy may still be different from a spherical assembly to a clump assembly. Figure 11 presents the distribution of contact force chains of fresh and fouled ballast (VCI $=25 \%$, and $50 \%$ ) at an axial strain of $\varepsilon_{a}=10 \%$ (i.e. the maximum deviatoric stress) subjected to a confining pressure of $\sigma_{3}^{\prime}=30 \mathrm{kPa}$. Note that 
force networks illustrated in Figure 11 are projections of axisymmetric 3D networks, where each branch of the network has a component in the out of plane direction. Contact forces between particles are plotted as lines whose thickness is proportional to the magnitude of the force. The contact forces are distributed non-uniformly throughout the assembly and transmitted vertically from the top plate to the bottom of the triaxial apparatus which is aligned in the direction of loading. It is seen here that while the number of contacts increases significantly with an increase of VCI, the maximum value of contact forces steadily decreases, thus the fouled ballast assemblies (Figure 11b and Figure 11c) show larger contact distributions and smaller maximum contact forces compared to those in fresh ballast (Figure 11a). The contact force distributions vary at different axial strain levels as particles are compacted and rearranged to support and transmit shearing loads throughout the assembly. As a result, different contact force networks could be formed at different loading stages. It is believed that the fine particles clogging the voids between the large aggregates partially transmit forces across the specimen, and as a result, denser contact force distributions (i.e. increased number of contacts) and a corresponding reduced maximum contact force magnitude are found in the fouled ballast assemblies (i.e. $2236 \mathrm{~N}$ for $50 \% \mathrm{VCI}$ fouled ballast compared to $3088 \mathrm{~N}$ for the fresh ballast). The fine would act as a 'cushioning layer' that could effectively reduce the inter-particle contact stresses and decrease the degradation of ballast aggregates which was observed in the laboratory as reported earlier by Indraratna et al. (2013a). It also decreases the shearing resistance as particles tend to roll and slide over each other due to decreased inter-particle friction.

Figure 12 presents spherical histograms of contact normal force orientations of fresh and fouled ballast assemblies subjected to a confining pressure of $\sigma_{3}^{\prime}=30 \mathrm{kPa}$ at varied axial strains of $\varepsilon_{a}=2 \%, 10 \%$, and $20 \%$, captured via DEM simulations. Orientations of contacts for granular assemblies were characterised by an angular distribution defining the portion of 
contacts falling within an angular interval (Figure 3b). In this study, a second-order fabric tensor introduced by Chantawarangul (1993) and Ouadfel and Rothernburg (2001) was used to quantify the anisotropy of fresh and fouled-ballast assemblies. A spherical histogram of contact forces was obtained by collecting contact force information at a specified bin angle (i.e. using a partitioning scheme for a sphere) and presented in solid angles of approximately the same substended area (Ouadfel and Rothenburg 2001). It is observed that when shearing $\left(\varepsilon_{a}=2 \%\right)$ commenced, there are more contacts orientated vertically than horizontally. The normal contact force anisotropy is approximately coaxial with vertical axes, having a principal direction of around $\theta_{r}=8^{0}$ (Figure 12a). An increase in the axial strain and the corresponding increased lateral deformation would facilitate the redistribution and reorientation of contact forces (i.e. the contact forces change directions and magnitudes from vertically orientated contacts to horizontally orientated contacts). The orientation of contact forces which tends to align towards the horizontal axis can be attributed to increased number of contacts in a horizontal plane, and they reach their values of approximately $\theta_{r}=17^{0}, 25^{0}$ at corresponding axial strains of $\varepsilon_{a}=10 \%$, and $\varepsilon_{a}=20 \%$, as shown in Figure $12 \mathrm{~b}$-c, respectively.

To show how the fouling could modify the force transmission pattern, spherical histograms of the contact force orientations for fresh and fouled ballast subjected to a confining pressure of $\sigma_{3}^{\prime}=30 \mathrm{kPa}$ at $\varepsilon_{a}=8 \%$ (i.e. approximately when the deviatoric stress reached its peak value) are analysed and presented in Figure 12d-f. The corresponding histograms indicate that there is a predominant distribution of contact forces in a vertical direction for both the fresh and fouled ballast. In the fresh ballast assembly, major contact force is transmitted with a principal direction of around $\theta_{r}=15^{0}$, whereas the force transmission in fouled ballast had contact force orientations of approximately $\theta_{r}=27^{0}$, and $34^{0}$ for the assemblies with a 
VCI $=25 \%$ and $50 \%$, respectively. These observations can be attributed to a greater number of contact forces observed in the fouled ballast assembly.

\section{Evolutions of fabric anisotropy}

Figure 13 presents the plots of induced anisotropies versus axial strain on fresh and fouled ballast ( $\mathrm{VCI}=25 \%$ and $50 \%$ ) subjected to a confining pressure of $\sigma_{3}^{\prime}=30 \mathrm{kPa}$. It is noted that the contact and force anisotropies presented in Figure 13 were carried out in a complete 3-dimensional analysis by comparing the fabric anisotropies captured in DEM simulations with those determined analytically given by Ouadfel and Rothenburg (2001) and Chantawarangul (1993). It is observed that the normal contact force anisotropy $a^{n}$, and the shear contact force anisotropy $a^{s}$ exhibit an identical trend, where they increase significantly at the beginning of the tests and reach peak values at relatively low axial strain levels of around $\varepsilon_{a}=3 \%-5 \%$. As shown in Figure 13, the fresh ballast exhibits a higher level of contact normal force anisotropy than the fouled ballast assemblies at low axial strain (i.e. $\varepsilon_{a}<15 \%$ ), but afterwards the value of $a^{n}$ for all assemblies almost converge together at the end of the test (i.e. steady state). The shear contact force anisotropy $a^{s}$ has only mobilised significantly at low axial strain $(<7 \%)$ and its effect seems to be negligible at higher axial strain levels. The contact anisotropy, $a^{r}$, on the other hand, is almost zero initially, and it attains a low value of about 0.02 within $5 \%$ axial strain, and then it increases significantly when the ballast assemblies begin to dilate after attaining a threshold compression at an axial strain of around 5\%. It is also observed from Figure 13 that only when $a^{s}$ starts to decrease (i.e. initiation of slippage and dilation) from its peak value beyond $4 \%$ axial strain that there is a significant increase in the rate of mobilisation of $a^{r}$ and this trend is more pronounced for fresh ballast. While the contact anisotropy, $a^{r}$ of the fresh ballast increases steadily and reaches a peak value of 0.1 at an axial strain of $\varepsilon_{a}=17 \%$, the value of $a^{r}$ for the fouled 
ballast gradually increases and attains a peak value of approximately 0.05 and 0.03 for the assembly of $\mathrm{VCI}=25 \%$ and $\mathrm{VCI}=50 \%$, respectively.

The micromechanical analysis presented in this study focusses on the evolution of contact force distributions and fabric anisotropy of fresh and fouled ballast at varying axial strains. This provides more insight into the orientation of contacts transmitted in fresh and fouled ballast assemblies. It is believed that inherent anisotropy affects the overall shear strength of ballast assemblies, while stresses inside the ballast medium are composed of multiple stress chains, which can lead to localised high stress concentrations within the assembly. Such high stress concentrations may lead to crushing of single particles even under relatively low applied stresses. In addition to this, the micromechanical analysis carried out in this study provides a fundamental framework of the anisotropic microstructure characteristics of the fouled-ballast which is expected to describe the behaviour of the fouled ballast more realistically. Therefore, understanding the anisotropy and contact force distribution in the ballast assemblies and its evolution is very useful.

\section{Practical implications and model limitations}

Results obtained from this study indicate that the fouled particles have considerable influence on the performance of railway ballast where excessive fouling seriously decreases the ballast shear strength of ballast, hence the risk associated with ballast fouling needs to be considered in track design. In low-lying coastal areas in Australia, where clay fouling often occurs under wet conditions, the reduced friction angle needs to be evaluated as a function of void contamination (Tennakoon et al. 2012) to avoid over-predicting the track bearing capacity in design. In addition to this, the evolution of contact orientations and fabric anisotropy obtained from this DEM model provides insightful information into how the fouled particles change 
the force transmission and the associated volume changes of a ballast assembly at a given confining pressure. The study also provides a fundamental numerical framework that can be easily accommodated in design practices from a micromechanical perspective.

The current DEM analysis still has several limitations which require further study, as mentioned below:

- From a micro-mechanical perspective, fine particles with irregular shapes (e.g. platelets) and realistic sizes (e.g. less than $1 \mathrm{~mm}$ ) should be modelled to provide a better understanding of the influence of fouling materials on the mobilised friction angle and volumetric change behaviour of fouled ballast.

- Further research should be conducted to fully capture the effect of moisture and associated micro-cohesion (adhesion) of clay fouled ballast on its stress-strain behaviour, where the moisture effect was not considered in the current analysis. Also, the effects of the fouling materials on the degradation of ballast aggregates need to be accurately captured in the DEM analysis, as void filling with clay provides a cushioning effect against stress concentrations and abrasion.

\section{Conclusions}

This paper presented the results of large-scale triaxial laboratory tests and numerical modelling using the discrete element method (DEM) to study the mobilised friction angle and volumetric change behaviour of fresh and clay-fouled ballast subjected to monotonic loading. The influence of fouling material on the strength and deformation of ballast was assessed in the laboratory using a series of monotonically loaded triaxial tests at various levels of fouling ranging from $\mathrm{VCI}=10 \%$ to $50 \%$ and subjected to three confining pressures of $10 \mathrm{kPa}$, $30 \mathrm{kPa}$ and $60 \mathrm{kPa}$. DEM simulations were performed on fresh and fouled ballast (VCI=25\% 
and $50 \%$ ) to study the mobilised friction angle and corresponding volumetric change of this granular assembly. For a given confining pressure and VCI, the model was able to capture the mobilised friction angle of fouled ballast as observed in the laboratory. As expected, the highest friction angle was observed in fresh ballast, but it decreased consistently with an increase in the level of fouling for a given value of confining pressure. Also, an increase in the level of fouling resulted in a considerable decrease in the mobilised friction angles.

A micromechanical analysis was used to investigate the contact force orientations and fabric anisotropy of fresh and fouled ballast. The results obtained from the simulations indicated that while the number of contacts increased significantly with an increased level of fouling, the peak value of the contact force decreased considerably. When subjected to monotonic shearing a contact force anisotropy developed that rotated to resist the shear stress and transmitted loads across the ballast grains that changed the contact direction from vertically orientated to more horizontally orientated. In the fresh ballast assembly, the major contact force had a principal direction around $15^{\circ}$, whereas in the fouled ballast the contact force was more uniformly distributed in all orientations had contact force orientations of around $27^{0}$, and $34^{0}$ for the case of VCI $=25 \%$ and $50 \%$, respectively. The contact normal and shear force anisotropies of fresh and fouled ballast increased markedly at the beginning of the tests and reached peak values at axial strain levels of 3\%-5\% before gradually decreasing towards the end of the tests. The contact anisotropy for the fresh and fouled ballast was very low initially, until it reached 5\% axial strain and then it started to increase significantly. Such a micromechanical investigation would enable practising engineers to insightfully examine evolutions of volumetric changes and the corresponding stress-strain behaviour of actual ballast aggregates while simulating geotechnical processes in the laboratory through physical modelling. 


\section{Acknowledgement}

The authors would like to express sincere appreciation to the Australian Research Council (ARC) for providing funding to this Project through the ARC Centre of Excellence in Geotechnical Science and Engineering and ARC-Linkage. The authors acknowledge Dr. Nayoma Tennakoon for conducting all the experiment used in this study. The authors would also like to thank technical staff at the University of Wollongong (Alan Grant, Cameron Neilson and Ian Bridge) for their assistance in the laboratory throughout the period of this study. The authors are grateful to Professor Glenn McDowell who provided suggestions to improve the paper significantly during the preparation of the paper. 


\section{Notations}

$a^{r} \quad$ coefficient of contact anisotropy

$a^{n} \quad$ coefficient of normal force anisotropy

$a^{s} \quad$ coefficient of shear force anisotropy

$d$ distance between the particle to particle centre

$e_{f} \quad$ void ratio of fouling material

$e_{b} \quad$ void ratio of fresh ballast

$\overrightarrow{\boldsymbol{F}}_{N} \quad$ normal force vector

$\overrightarrow{\boldsymbol{F}}_{T} \quad$ shear force vector

$\delta \overrightarrow{\boldsymbol{F}}_{T} \quad$ incremental shear force

$G_{s . b} \quad$ specific gravity of ballast

$G_{s . f} \quad$ specific gravity of fouling material

$k_{n} \quad$ contact normal stiffness

$k_{s} \quad$ contact shear stiffness

$k_{n \text {-wall }}$ contact normal stiffness of wall-particle

$k_{s-w a l l}$ contact shear stiffness of wall-particle

$M_{f} \quad$ dry mass of fouling material

$M_{b} \quad$ dry mass of fresh ballast

$n_{i} \quad$ unit vector

$p \quad$ mean stress

$q \quad$ deviatoric stress

$R^{[A]}, R^{[B]} \quad$ radii of particles $A, B$

$U^{n} \quad$ normal contact displacement

VCI Void Contamination Index

$\mu \quad$ inter-particle friction coefficient

$x_{i}^{[A]}, x_{i}^{[B]} \quad$ particle's centres 
$\delta U^{s} \quad$ incremental shear displacement

$\sigma_{1}^{\prime} \quad$ axial stress

$\sigma_{3}^{\prime} \quad$ confining pressure

$\varepsilon_{a} \quad$ axial strain

$\varepsilon_{v} \quad$ volumetric strain

$\theta_{r} \quad$ major principal direction of contact anisotropy

$\phi \quad$ mobilised friction angle

$\phi_{p}^{\prime} \quad$ apparent peak friction angle 


\section{References}

Australian Standard. (1996). “Aggregates and rock for engineering purposes; Part 7: Railway ballast.” AS 2758.7. Sydney, Australia.

ASTM. (2003). "Standard test method for direct shear test of soils under consolidated drained conditions.” D3080-03. West Conshohocken, PA.

Anderson, W. F. , and Fair, P. (2008). "Behavior of railroad ballast under monotonic and cyclic loading". Journal of Geotechnical and Geoenvironmental Engineering. 143(3): 316-327.

Bolton, M.D. (1986). “The strength and dilatancy of sands”. Géotechnique. 36(1): 65-78.

Bhandari, A., Han, J. , and Wang, C. (2009). "Micromechanical analysis of soil arching in geosynthetic-reinforced pile-supported embankments". Geotechnical Special Publication 198, ASCE. 47-52.

Bhandari, A. and Han, J., 2010. Investigation of geotextile-soil interaction under a cyclic vertical load using the discrete element method. Geotextiles and Geomembranes, 28(1), pp.33-43.

Bolton, M. D., Nakata, Y. , and Cheng, Y. P. (2008). "Micro- and macro-mechanical behaviour of DEM crushable materials". Géotechnique. 58(6): 471-480.

Budiono, D. S., McSweeney, T., Dhanasekar, M. , and Gurung, N. (2004). "The effect of coal dust fouling on the cyclic behaviour of railtrack ballast". Cyclic Behaviour of Soils and Liquefaction phenomena. Taylor \& Francis Group, London.

Chantawarangul, K. (1993). Numerical simulations of three-dimensional granular assemblies.

Ph.D. thesis, University of Waterloo Department of Civil Engineering.

Cundall, P. A. , and Strack, O. D. L. (1979). "A discrete numerical model for granular assemblies". Géotechnique. 29(1): 47-65.

Dombrow, W., Huang, H. , and Tutumluer, E. (2009). "Comparison of coal dust fouled railroad ballast behavior- granite vs. limestone". Bearing Capacity of Roads, Railways and Airfields, Proceedings of the 8th International Conference (BCR2A'09). Taylor \& Francis Group.

Ebrahimi, A., Tinjum, J. M. , and Edil, T. B. (2014). "Deformational behavior of fouled railway ballast". Canadian Geotechnical Journal. 52(3): 344-355.

Ferellec, J. F. , and McDowell, G. R. (2008). "A simple method to create complex particle shapes for DEM". Geomechanics and Geoengineering. 3(3): 211 - 216.

Huang, H., Tutumluer, E., Hashash, Y. M. A. , and Ghaboussi, J. (2009). "Discrete element modeling of aggregate behavior in fouled railroad ballast". Geotechnical Special Publication, ASCE. 192: 33-41. 
Huang, H. , and Tutumluer, E. (2011). "Discrete element modeling for fouled railroad ballast". Construction and Building Materials. 25: 3306-3312.

Huang, J., da Silva, M. V. , and Krabbenhoft, K. (2013). "Three-dimensional granular contact dynamics with rolling resistance". Computers and Geotechnics. 49: 289-298.

Indraratna, B., Ionescu, D. , and Christie, D. (1998). "Shear behaviour of railway ballast based on large scale triaxial testing". Journal of Geotechnical and Geoenvironmental Engineering. 124(5): 439-449.

Indraratna, B., Thakur, P. K. , and Vinod, J. S. (2010). "Experimental and numerical study of railway ballast behavior under cyclic loading". International Journal of Geomechanics, ASCE. 10(4): 136-144.

Indraratna, B., Salim, W. , and Rujikiatkamjorn, C. (2011a). Advanced rail geotechnology ballasted track. CRC Press, Taylor \& Francis Group, London, UK.

Indraratna, B., Ngo, N. T. , and Rujikiatkamjorn, C. (2011b). "Behavior of geogrid-reinforced ballast under various levels of fouling". Geotextiles and Geomembranes. 29(3): 313322.

Indraratna, B., Tennakoon, N., Nimbalkar, S. , and Rujikiatkamjorn, C. (2013a). "Behaviour of clay-fouled ballast under drained triaxial testing". Géotechnique. 63(5): 410-419.

Indraratna, B., Ngo, N. T. , and Rujikiatkamjorn, C. (2013b). "Studying the deformation of coal fouled ballast stabilised with geogrid under cyclic load". Journal of Geotechnical and Geoenvironmental Engineering, ASCE. 139(8): 1275-1289.

Indraratna, B., Ngo, N. T, Rujikiatkamjorn, C. , and Vinod, J. (2014). "Behavior of fresh and fouled railway ballast subjected to direct shear testing: Discrete element simulation". International Journal of Geomechanics. 14(1): 34-44.

Indraratna, B., Ngo, N. T., Rujikiatkamjorn, C. , and Sloan, S. W. (2015). "Coupled discrete element-finite difference method for analysing the load-deformation behaviour of a single stone column in soft soil". Computers and Geotechnics. 63: 267-278.

Itasca (2014). "Particle flow code in three dimensions (PFC3D)". Itasca Consulting Group, Inc., Minnesota, USA.

Jiang. M.J., Yu, H.S., Harris, D.(2005). “A novel discrete model for granular material incorporating rolling resistance”. Computers and Geotechnics. 32 (2005) 340-357.

Lackenby, J., Indraratna, B., McDowell, G. R. , and Christie, D. (2007). "Effect of confining pressure on ballast degradation and deformation under cyclic triaxial loading". Géotechnique. 57(6): 527-536.

Lim, W. L. , and McDowell, G. R. (2005). "Discrete element modelling of railway ballast". Granular Matter. 7(1): 19-29. 
Lobo-Guerrero, S. , and Vallejo, L. E. (2005). "Discrete element method evaluation of granular crushing under direct shear test condition". Journal of Geotechnical and Geoenvironmental Engineering. 131(10): 1295-1300.

Lobo-Guerrero, S. , and Vallejo, L. E. (2010). "The effectiveness of geosynthetic reinforcement, tamping, and stoneblowing of railtrack ballast beds under dynamic loading: DEM analysis". Geomechanics and Engineering. 2(3): 161-171.

Lu, M., and McDowell, G. R. (2008). "Discrete element modelling of railway ballast under triaxial conditions". Geomechanics and Geoengineering: An International Journal. 3(4): 257-270.

Lu, M., and McDowell, G. R. (2010). "Discrete element modelling of railway ballast under monotonic and cyclic triaxial loading". Géotechnique. 60(6): 459-467.

McDowell, G. R., Harireche, O., Konietzky, H., Brown, S. F. , and Thom, N. H. (2006). "Discrete element modelling of geogrid-reinforced aggregates". Proceedings of the ICE - Geotechnical Engineering 159(1): 35-48.

Ngo, N. T., Indraratna, B. , and Rujikiatkamjorn, C. (2014). "DEM simulation of the behaviour of geogrid stabilised ballast fouled with coal". Computers and Geotechnics. 55(2014): 224-231.

Ngo, N.T., Indraratna, B., and Rujikiatkamjorn, C. (2015). "Experimental and discrete element modelling of geocell-stabilised sub-ballast under cyclic loading”. Journal of Geotechnical and Geoenvironmental Engineering, ASCE. DOI: 10.1061/(ASCE)GT.1943-5606.0001431.

Ni, J., Indraratna, B., Geng, X., Carter, J., and Chen, Y. (2014). "Model of soft soils under cyclic loading”. International Journal of Geomechanics. 10.1061/(ASCE)GM.19435622.0000411, 04014067.

Ni, Q., Powrie, W., Zhang, X. , and Harkness, R. (2000). "Effect of particle properties on soil behaviour: 3-D numerical modelling of shearbox test". Geotechnical Special Publication, ASCE. 96: 58-70.

O'Sullivan, C. , and Cui, L. (2009). "Micromechanics of granular material response during load reversals: Combined DEM and experimental study". Powder Technology. 193: 289-302.

O'Sullivan, C., Butlanska, J. , and Cheung, G. (2010 ). "Calculating strain in 3D DEM simulations". Materials Science and Engineering. 10: 1-10.

O'Sullivan, C. (2011). Particulate discrete element modelling: A geomechanics perspective, Taylor \& Francis.

Oda, M. (1982). "Fabric tensor for discontinuous geological materials". Soils and Foundations. 22(4): 96-108.

Oda, M. , and Iwashita, K. (1999). Mechanics of granular materials: An introduction, Rotterdam: A. A. Balkema. 
Ouadfel H, Rothenburg L. (2001). "Stress-force-fabric relationship for assemblies of ellipsoids”. Mechanics of Materials. 33(2001), pp:201-221.

Rothenburg, L. (1980). Micromechanics of idealized granular systems. PhD dissertation, Carleton University, Ottawa, Canada.

Rothenburg, L. , and Bathurst, R. J. (1989). "Analytical study of induced anisotropy in idealized granular materials". Géotechnique. 39(4): 601-614.

Selig, E. T. , and Waters, J. M. (1994). Track geotechnology and substructure management, Thomas Telford, London.

Suiker, A. S. J., Selig, E. T. , and Frenkel, R. (2005). "Static and cyclic triaxial testing of ballast and subballast". Journal of Geotechnical and Geoenvironmental Engineering, ASCE 131(6): 771-782.

Tennakoon, N., Indraratna, B., Rujikiatkamjorn, C., Nimbalkar, S., and Neville, T. (2012). "The role of ballast fouling characteristics on the drainage capacity of rail substructure”. Geotechnical Testing Journal, ASTM. 35(4): 1-12.

Trani, L. D. O. , and Indraratna, B. (2010). "Assessment of subballast filtration under cyclic loading". Journal of Geotechnical and Geoenvironmental Engineering. 136(11): 1519-1528.

Tutumluer, E., Huanng, H., Hashash, Y. M. A. , and Ghaboussi, J. (2007). "Discrete element Modeling of Railroad Ballast Settlement". Proceedings of the 2007 AREMA Annual Conference, Chicago, Illinois.

Tutumluer, E., Dombrow, W. , and Huang, H. (2008). "Laboratory characterization of coal dust fouled ballast behaviour". AREMA 2008 Annual Conference \& Exposition, Salt Lake City, UT, USA.

Tutumluer, E., Huang, H. , and Bian, X. (2012). "Geogrid-aggregate interlock mechanism investigated through aggregate imaging based discrete element modeling approach". International Journal of geomechanics, ASCE. 12(4): 391-398.

Wang, J., Dove, J. E. , and Gutierrez, M. (2007). "Discrete-continuum analysis of shear banding in the direct shear test". Géotechnique. 57(6) pp: 513-526.

Zhang, X., Krabbenhoft, K., Pedroso, D. M., Lyamin, A. V., Sheng, D., da Silva, M. V. , and Wang, D. (2013). "Particle finite element analysis of large deformation and granular flow problems". Computers and Geotechnics. 54: 133-142. 


\section{List of Tables}

Table 1. Properties of materials tested

\begin{tabular}{l|l}
\hline Property & Value \\
\hline Specific gravity of ballast, $G_{s b}$ & 2.75 \\
Specific gravity of clay, $G_{s f}$ & 2.51 \\
Unit weight of fresh ballast: $\mathrm{kN} / \mathrm{m}^{3}$ & 14.3 \\
Uniaxial compressive strength of parent rock, $\sigma_{c}: \mathrm{MPa}$ & 130 \\
Unit weight of clay: $\mathrm{kN} / \mathrm{m}^{3}$ & 15.5 \\
Initial void ratio of clay, $e_{f}$ & 1.75 \\
Plastic limit of clay: \% & 26.4 \\
Liquid limit of clay: \% & 52.1 \\
\hline
\end{tabular}


Table 2. Parameters used to calibrate the clay

\begin{tabular}{|l|l|l|l|}
\hline & $\begin{array}{l}\text { Normal stiffness, } k_{n} \\
(\mathrm{~N} / \mathrm{m})\end{array}$ & $\begin{array}{l}\text { Shear stiffness, } k_{s} \\
(\mathrm{~N} / \mathrm{m})\end{array}$ & Friction coefficient, $\mu$ \\
\hline Simulation 1 & $0.52 \times 10^{4}$ & $0.86 \times 10^{4}$ & 0.25 \\
\hline Simulation 2 & $3.72 \times 10^{4}$ & $3.72 \times 10^{4}$ & 0.25 \\
\hline Simulation 3 & $1.48 \times 10^{5}$ & $0.24 \times 10^{5}$ & 0.25 \\
\hline Simulation 4 & $2.64 \times 10^{5}$ & $1.32 \times 10^{5}$ & 0.25 \\
\hline
\end{tabular}


Table 3.Micromechanical parameters of ballast and clay adopted for DEM simulation

\begin{tabular}{l|l|l}
\hline Parameter & Ballast & Clay \\
\hline Particle density $\left(\mathrm{kg} / \mathrm{m}^{3}\right)$ & 2750 & 2510 \\
Friction coefficient, $\mu$ & 0.8 & 0.25 \\
Contact normal stiffness, $k_{n}(\mathrm{~N} / \mathrm{m})$ & $0.52 \times 10^{8}$ & $3.72 \times 10^{4}$ \\
Contact shear stiffness, $k_{s}(\mathrm{~N} / \mathrm{m})$ & $0.52 \times 10^{8}$ & $3.72 \times 10^{4}$ \\
Contact normal stiffness of wall, $k_{n \text {-wall }}(\mathrm{N} / \mathrm{m})$ & $1.0 \times 10^{8}$ & $1.0 \times 10^{8}$ \\
Shear stiffness of wall of wall, $k_{s-\text { wall }}(\mathrm{N} / \mathrm{m})$ & $1.0 \times 10^{8}$ & $1.0 \times 10^{8}$ \\
Number of added balls to simulate fouling, VCI=25\% & & 132,637 \\
Number of added balls to simulate fouling, VCI=50\% & & 316,224 \\
\hline
\end{tabular}




\section{Figure Caption List}

Figure 1: (a) Particle size distribution of materials tested; (b) ballast mixed with kaolin; and (c) fouled ballast (VCI=50\%)

Figure 2. Experimental results of clay-fouled ballast: (a) mobilised friction angles; (b) variations of dilation angle with VCI ; (c) variations of peak friction angle with VCI.

Figure3. (a) notation used to describe contacts in DEM, (b) elementary solid angle in spherical coordinate system.

Figure 4. Large-scale triaxial test for ballast: (a) ballast sample tested in the laboratory; (b) side view of DEM model; (c) plane view of the DEM model; (d) photo of large-scale triaxial apparatus; and (e) schematic illustration of large-scale triaxial apparatus.

Figure 5. Irregular shaped ballast particles used in the DEM analysis

Figure 6. DEM predictions compared with experimental data of fresh ballast at varied confining pressures, $\sigma_{3}^{\prime}=10 \mathrm{kPa}, 30 \mathrm{kPa}$, and $60 \mathrm{kPa}:(a)$ mobilised friction angle, $\phi ;(b)$ volume change behaviour, $\varepsilon_{v}$

Figure 7. DEM simulation of a direct shear test

Figure 8. Parametric study of micromechanical parameters for fouling material: (a) Friction coefficient, $\mu$; (b) contact normal and shear stiffness; and (c) volumetric changes

Figure 9. Comparisons of mobilised friction angles and volumetric strain responses between DEM simulation and experiment for fouled ballast :(a) $\mathrm{VCI}=25 \%$; (b) $\mathrm{VCI}=50 \%$

Figure 10. Variations of deviatoric and mean stresses of fresh and fouled ballast obtained from experiment and DEM simulation: (a) fresh ballast; (b) VCI=25\%; and (c) VCI=50\% Figure 11. Contact force distributions of fresh and fouled ballast in simulated triaxial tests: (a) $\mathrm{VCI}=0 \%$; (b) $\mathrm{VCI}=25 \%$; (c) $\mathrm{VCI}=50 \%$ 
Figure 12. Spherical histograms of contact orientations for fresh and fouled ballast at different axial strains and VCI: (a) $\varepsilon_{a}=2 \%$; (b) $\varepsilon_{a}=10 \%$; (c) $\varepsilon_{a}=20 \%$; (d) VCI=0\%; (e) VCI=25\%; (f) $\mathrm{VCI}=50 \%$.

Figure 13. Evolutions of the anisotropy of fresh and fouled ballast at a confining pressure of $30 \mathrm{kPa}$ :

(a) anisotropy of normal force, $a^{n}$; (b) anisotropy of shear force, $a^{s}$; (c) anisotropy of normal contact, $a^{r}$. 


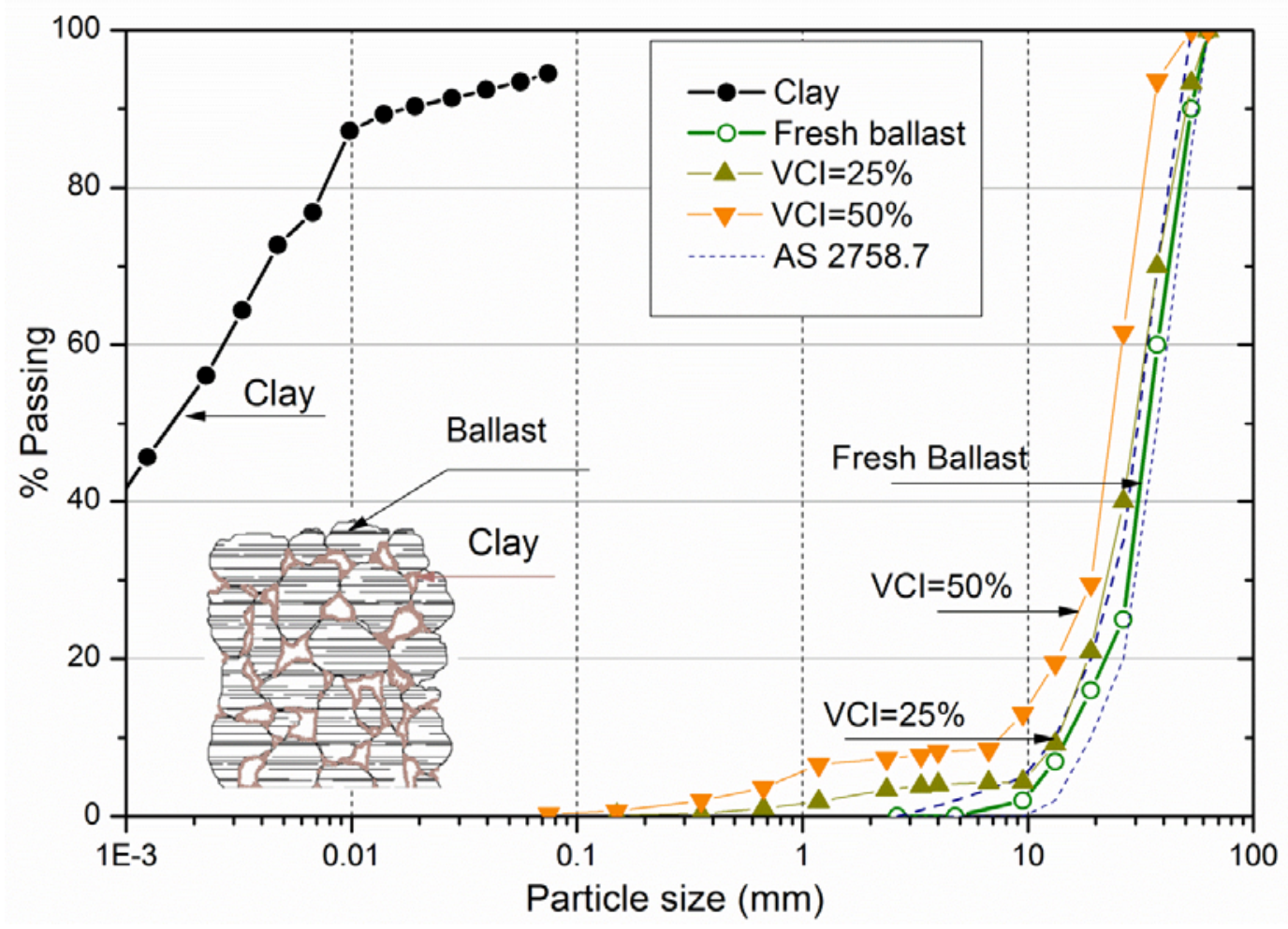

(a)

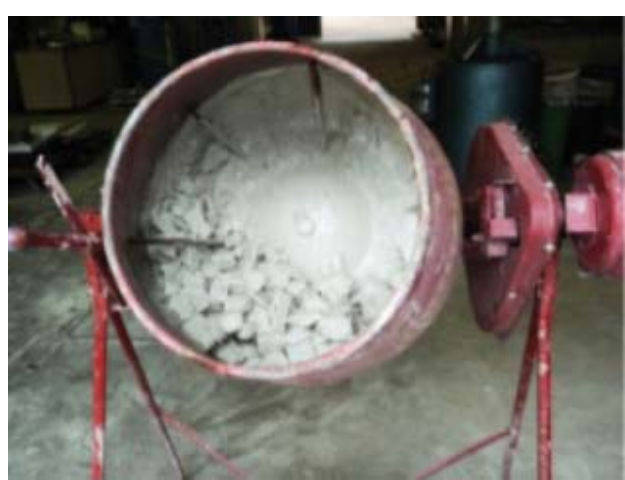

(b)

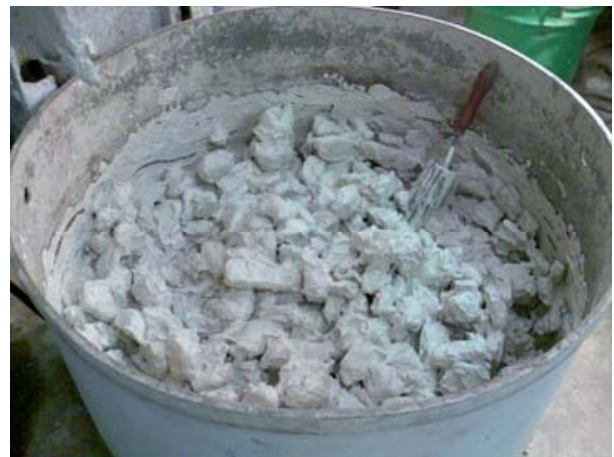

(c)

Figure 1: (a) Particle size distribution of materials tested; (b) ballast mixed with kaolin; and (c) fouled ballast (VCI=50\%) 


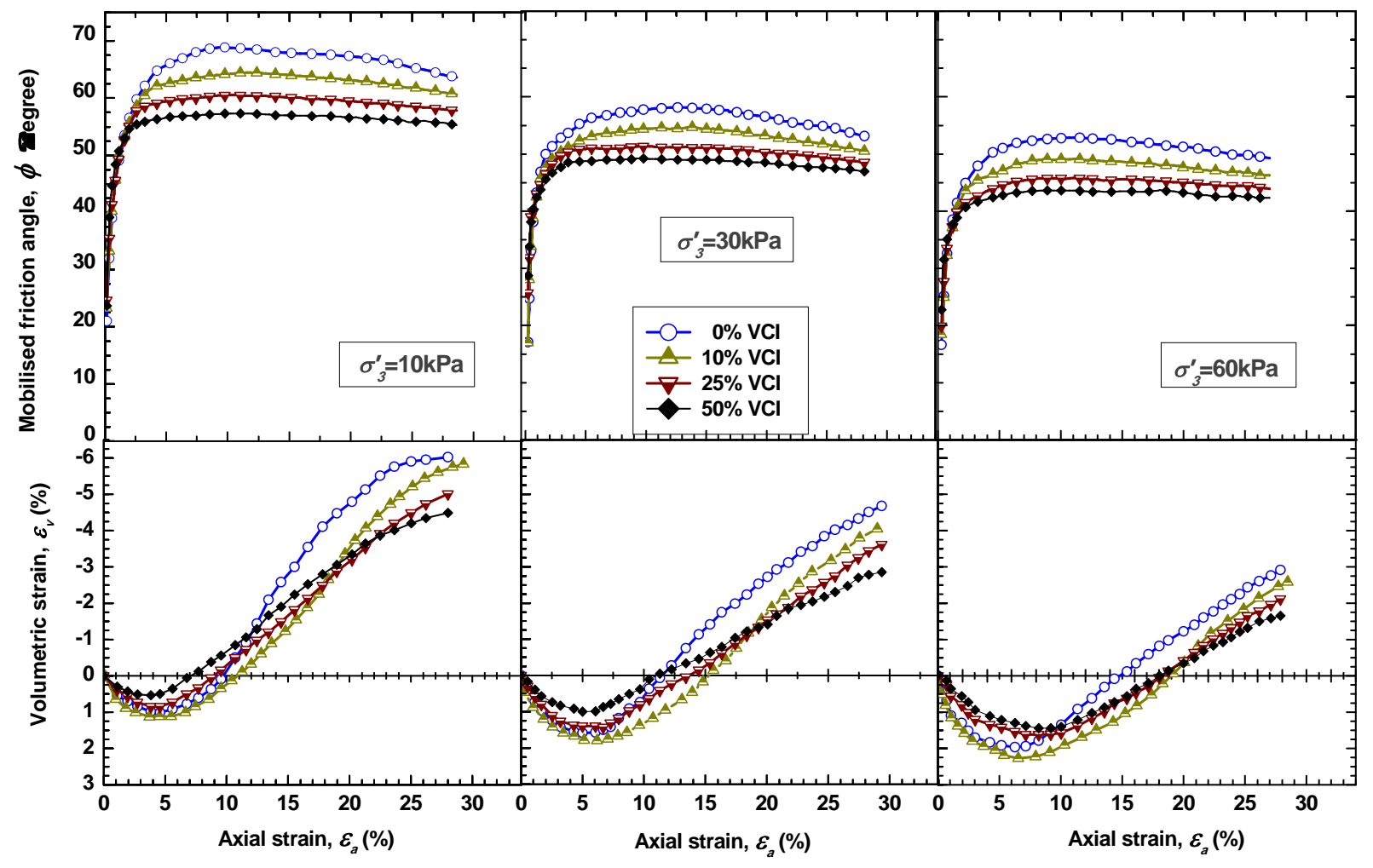

(a)

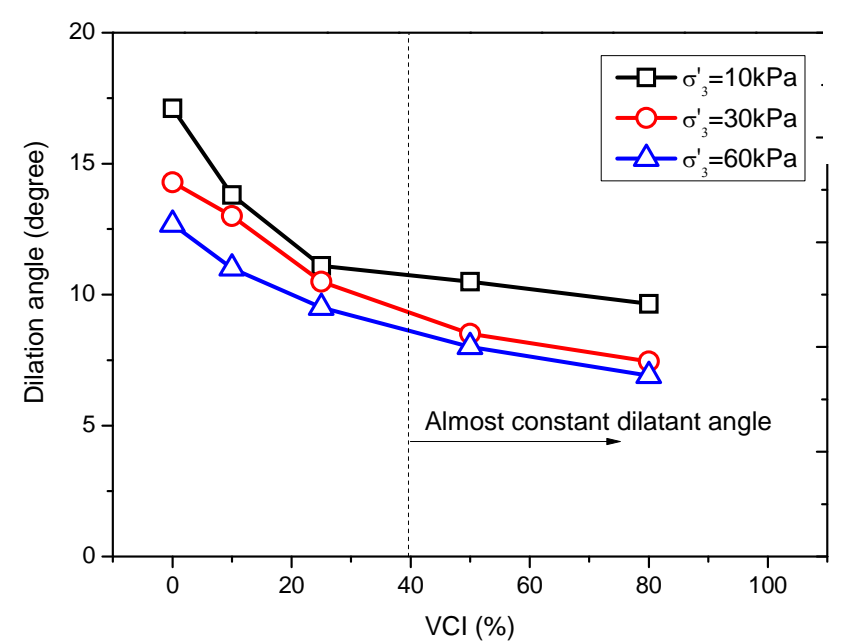

(b)

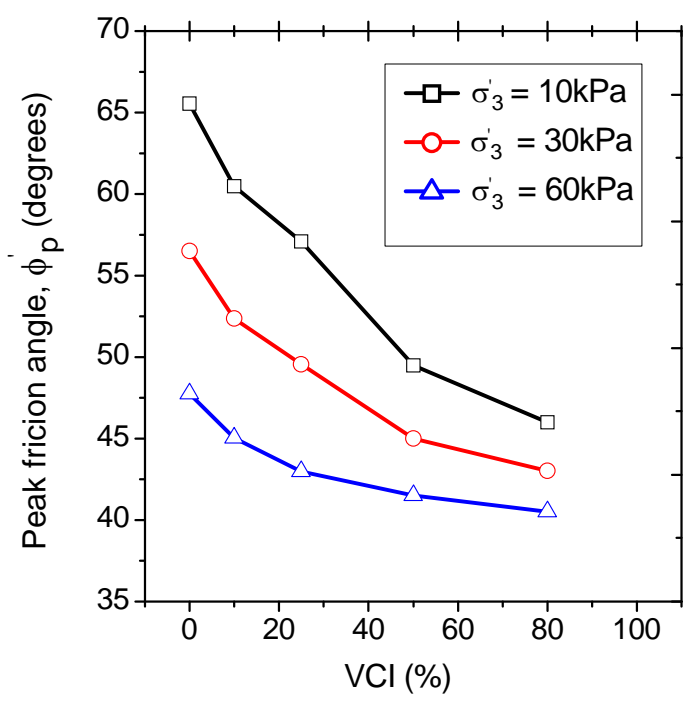

(c)

Figure 2. Experimental results of clay-fouled ballast: (a) mobilised friction angles; (b) variations of dilation angle with VCI ; (c) variations of peak friction angle with VCI. 


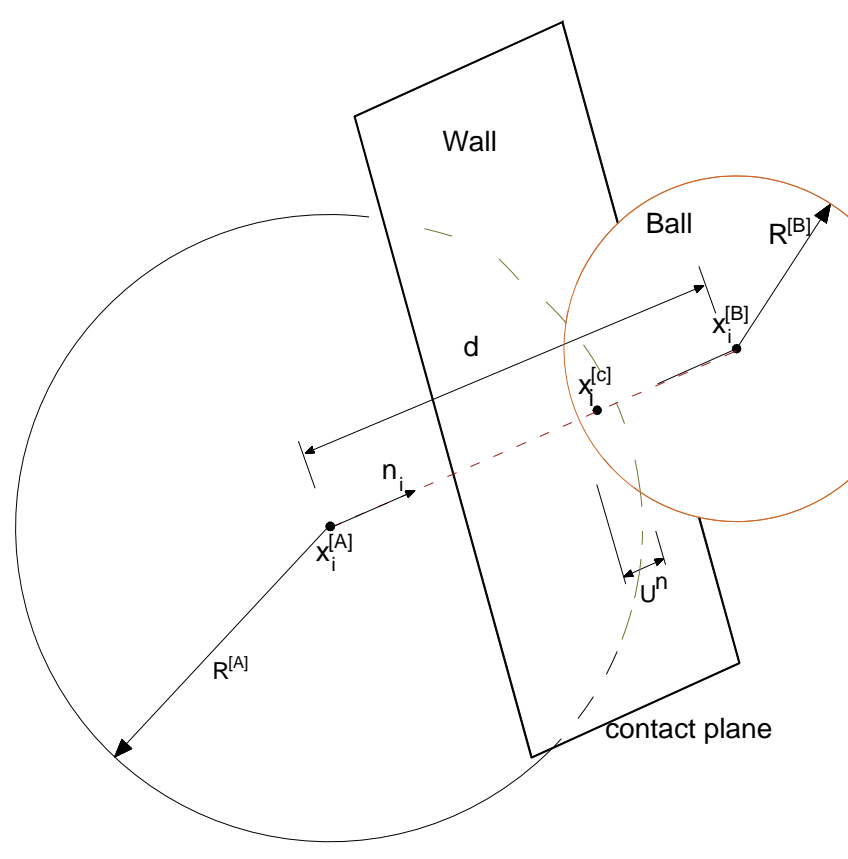

(a)

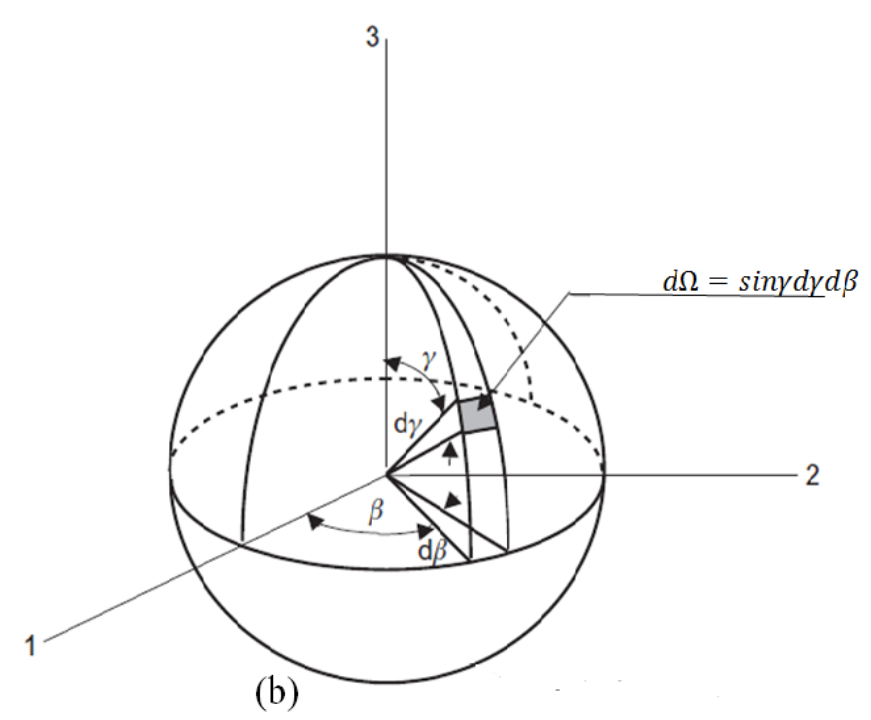

Figure3. (a) notation used to describe contacts in DEM, (b) elementary solid angle in spherical coordinate system. 


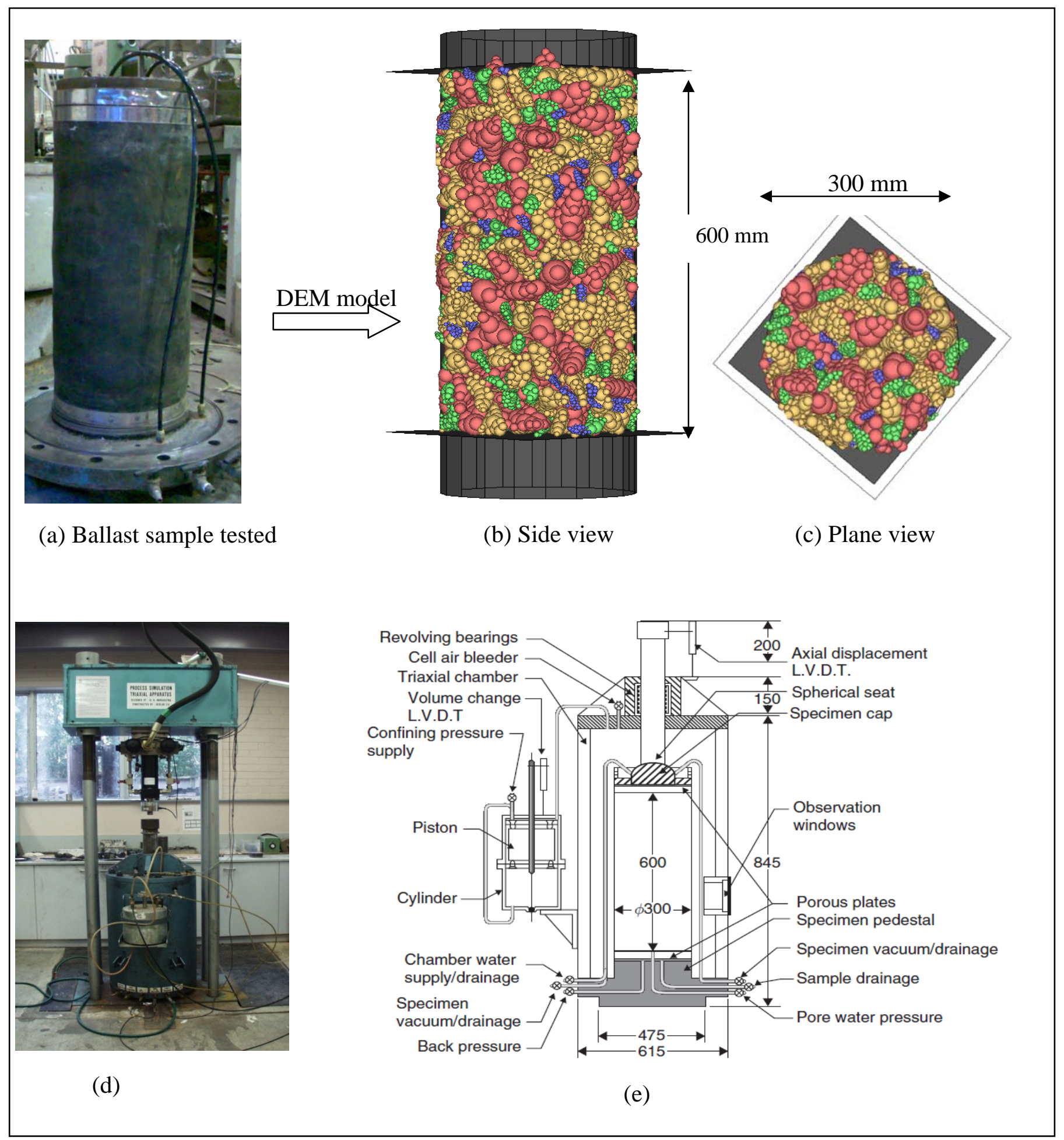

Figure 4. Large-scale triaxial test for ballast: (a) ballast sample tested in the laboratory; (b) side view of DEM model; (c) plane view of the DEM model; (d) photo of large-scale triaxial apparatus; and (e) schematic illustration of large-scale triaxial apparatus. 


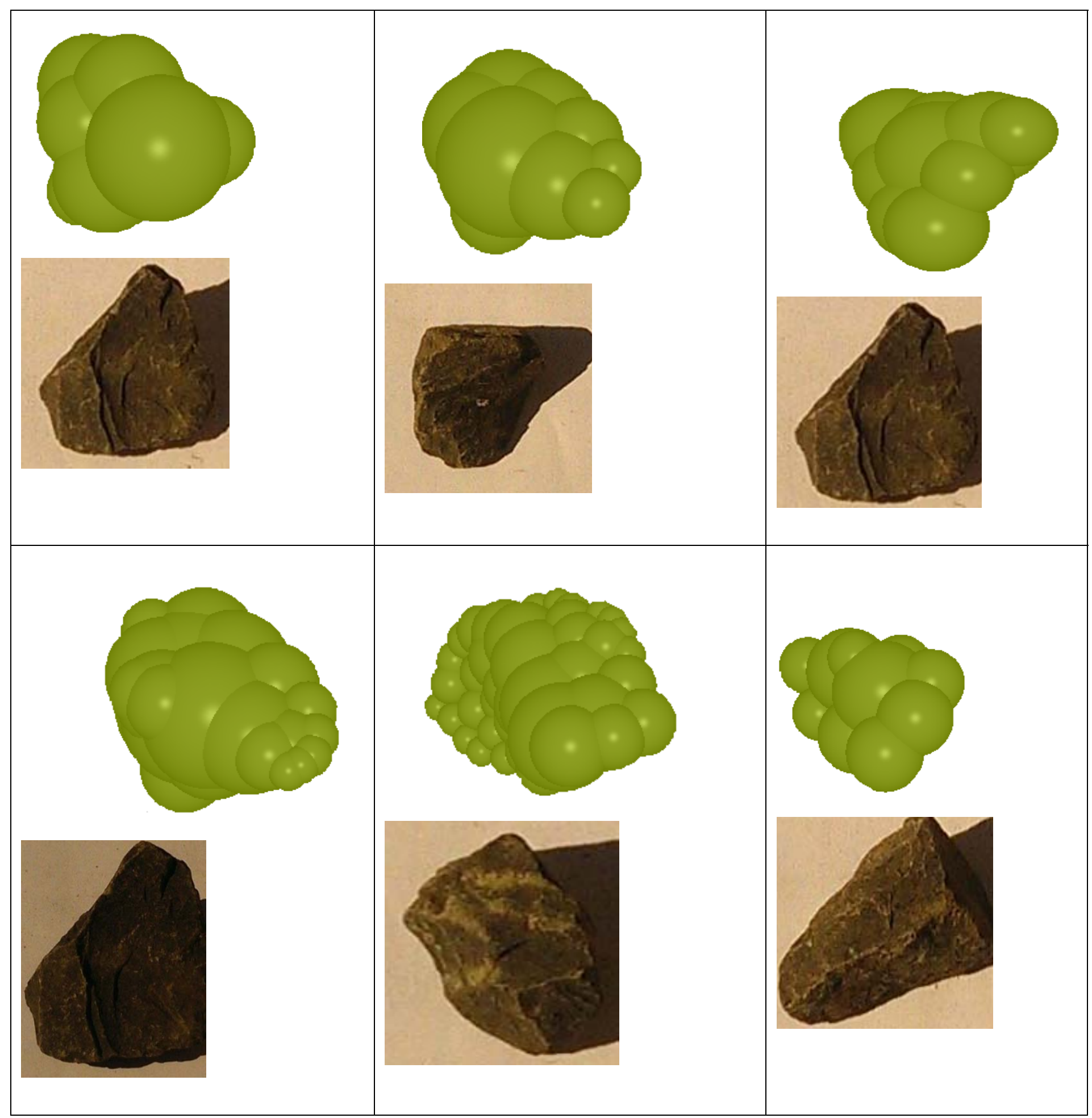

Figure 5. Irregular shaped ballast particles used in the DEM analysis 


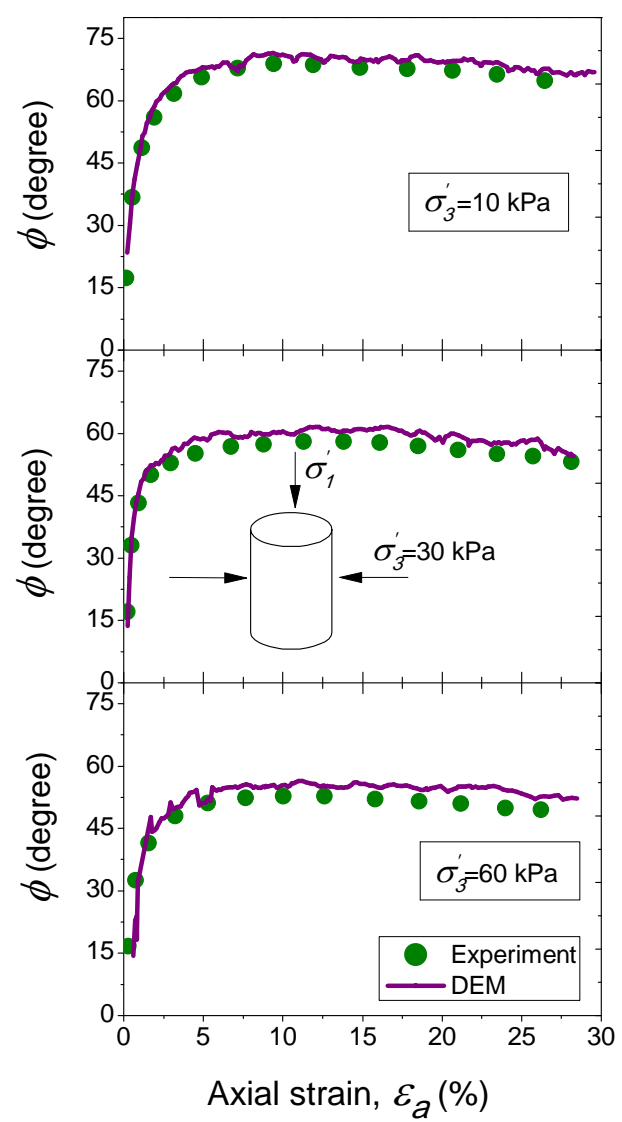

(a)

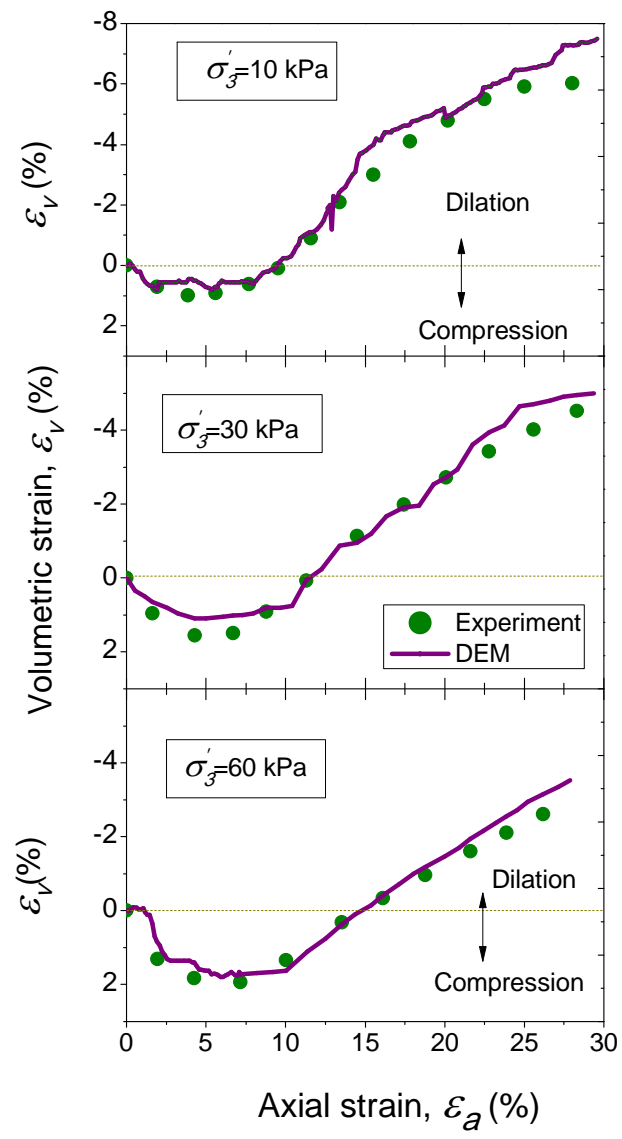

(b)

Figure 6. DEM predictions compared with experimental data of fresh ballast at varied confining pressures, $\sigma_{3}^{\prime}=10 \mathrm{kPa}, 30 \mathrm{kPa}$, and $60 \mathrm{kPa}:(a)$ mobilised friction angle, $\phi ;(b)$ volume change behaviour, $\varepsilon_{v}$ 




Figure 7. DEM simulation of a direct shear test 

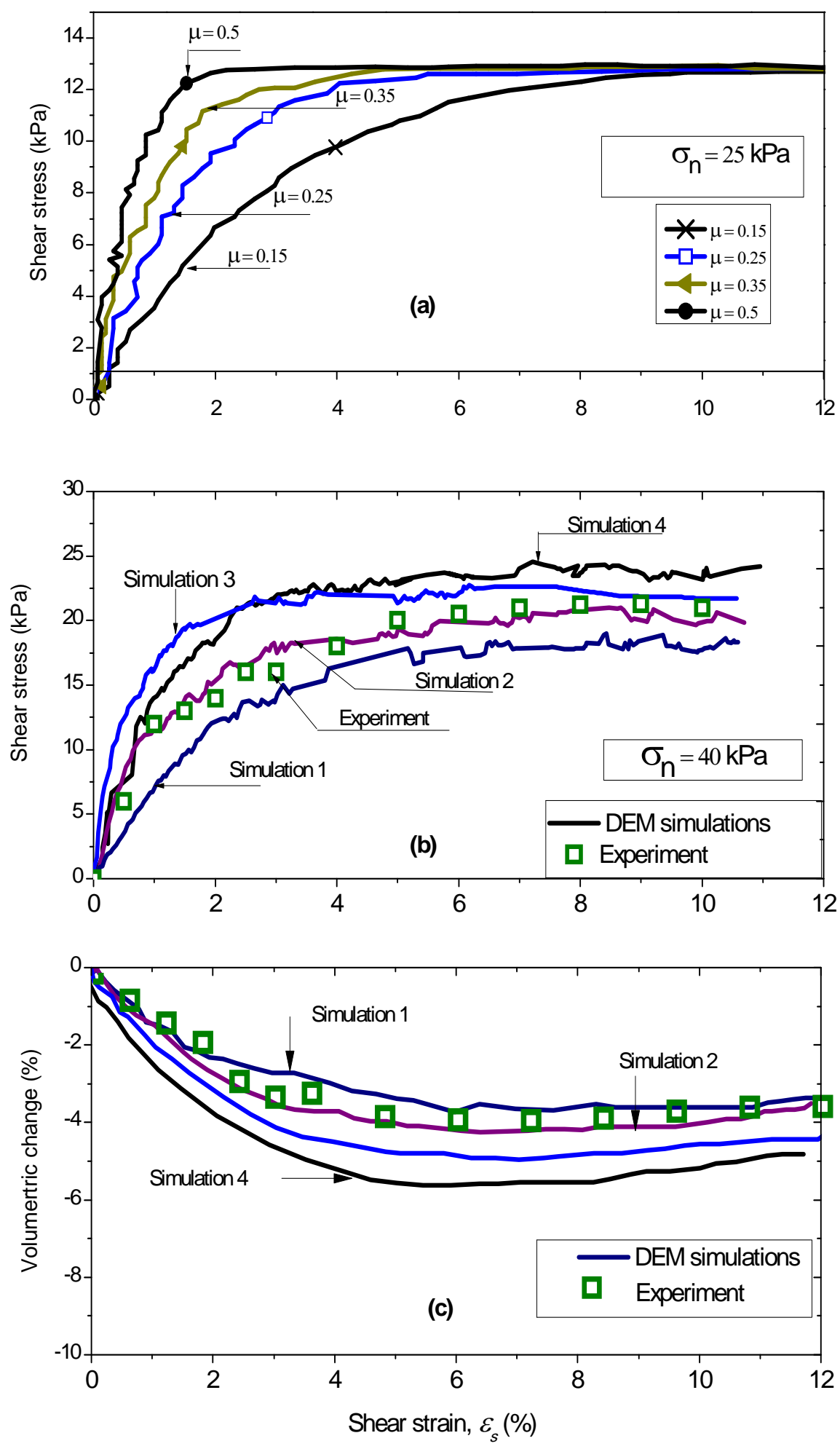

Figure 8. Parametric study of micromechanical parameters for fouling material: (a) Friction coefficient, $\mu$; (b) contact normal and shear stiffness; and (c) volumetric changes 


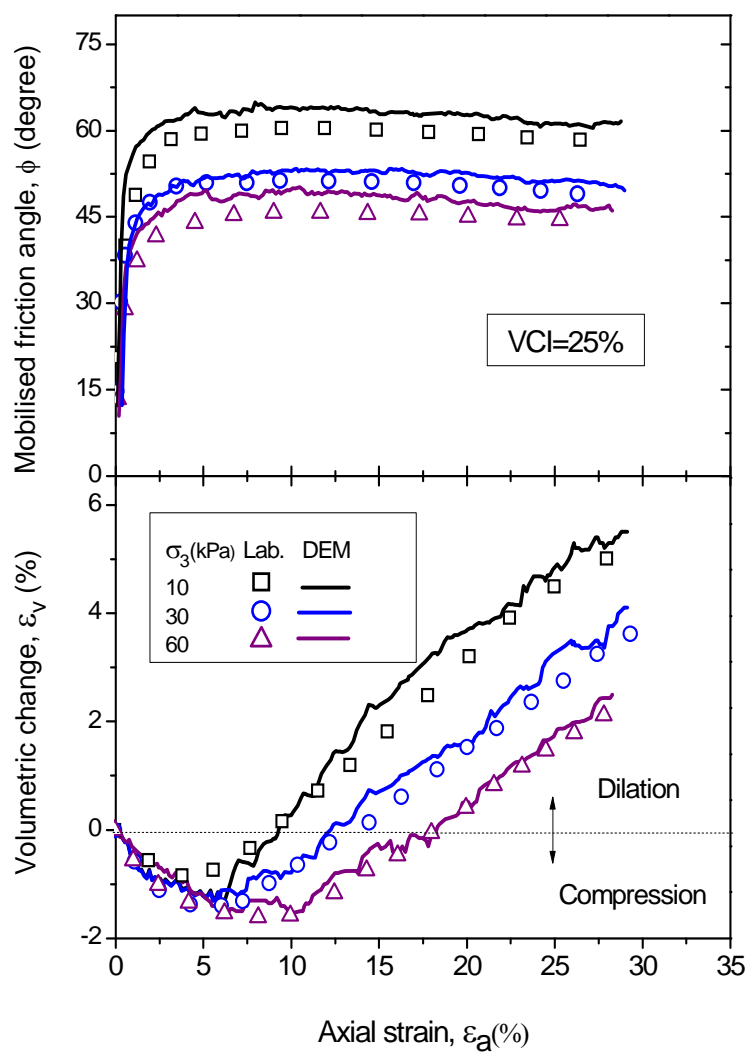

(a)

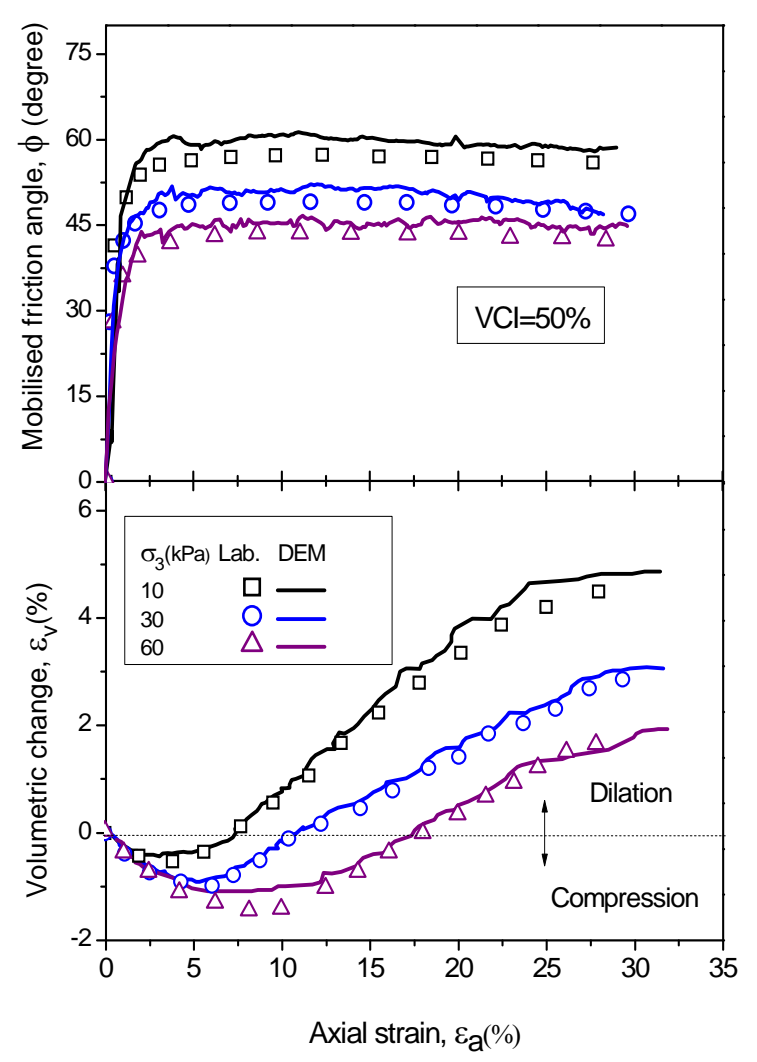

(b)

Figure 9. Comparisons of mobilised friction angles and volumetric strain responses between DEM simulation and experiment for fouled ballast :(a) VCI=25\%; (b) VCI=50\% 


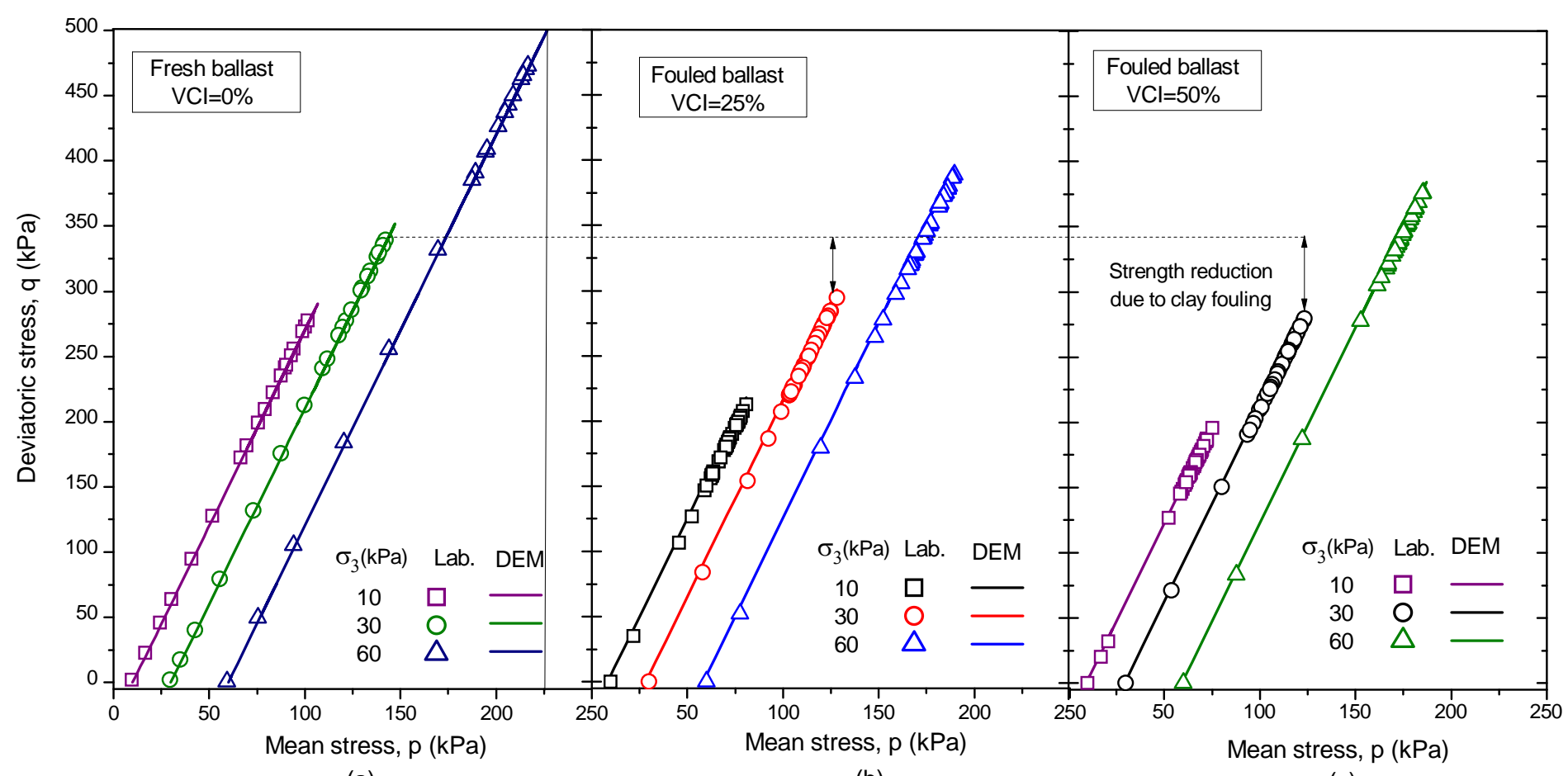

(a)

(b)

(c)

Figure 10. Variations of deviatoric and mean stresses of fresh and fouled ballast obtained from experiment and DEM simulation: (a) fresh ballast; (b) VCI $=25 \%$; and (c) VCI $=50 \%$ 



(a) $\mathrm{VCI}=0 \%$

Number of contacts: 170,568

Maximum force: $3088(\mathrm{~N})$

(b) $\mathrm{VCI}=25 \%$

Number of contacts: 427,214

Maximum force: $2488(\mathrm{~N})$



(c) $\mathrm{VCI}=50 \%$

Number of contacts: 736,537

Maximum force: $2236(\mathrm{~N})$

Figure 11. Contact force distributions of fresh and fouled ballast in simulated triaxial tests: (a) VCI=0\%; (b) VCI=25\%; (c) VCI=50\% 



Figure 12. Spherical histograms of contact orientations for fresh and fouled ballast at different axial strains and VCI: (a) $\varepsilon_{a}=2 \%$; (b) $\varepsilon_{a}=10 \%$; (c) $\varepsilon_{a}=20 \%$; (d) VCI=0\%; (e) VCI $=25 \%$; (f) VCI $=50 \%$. 


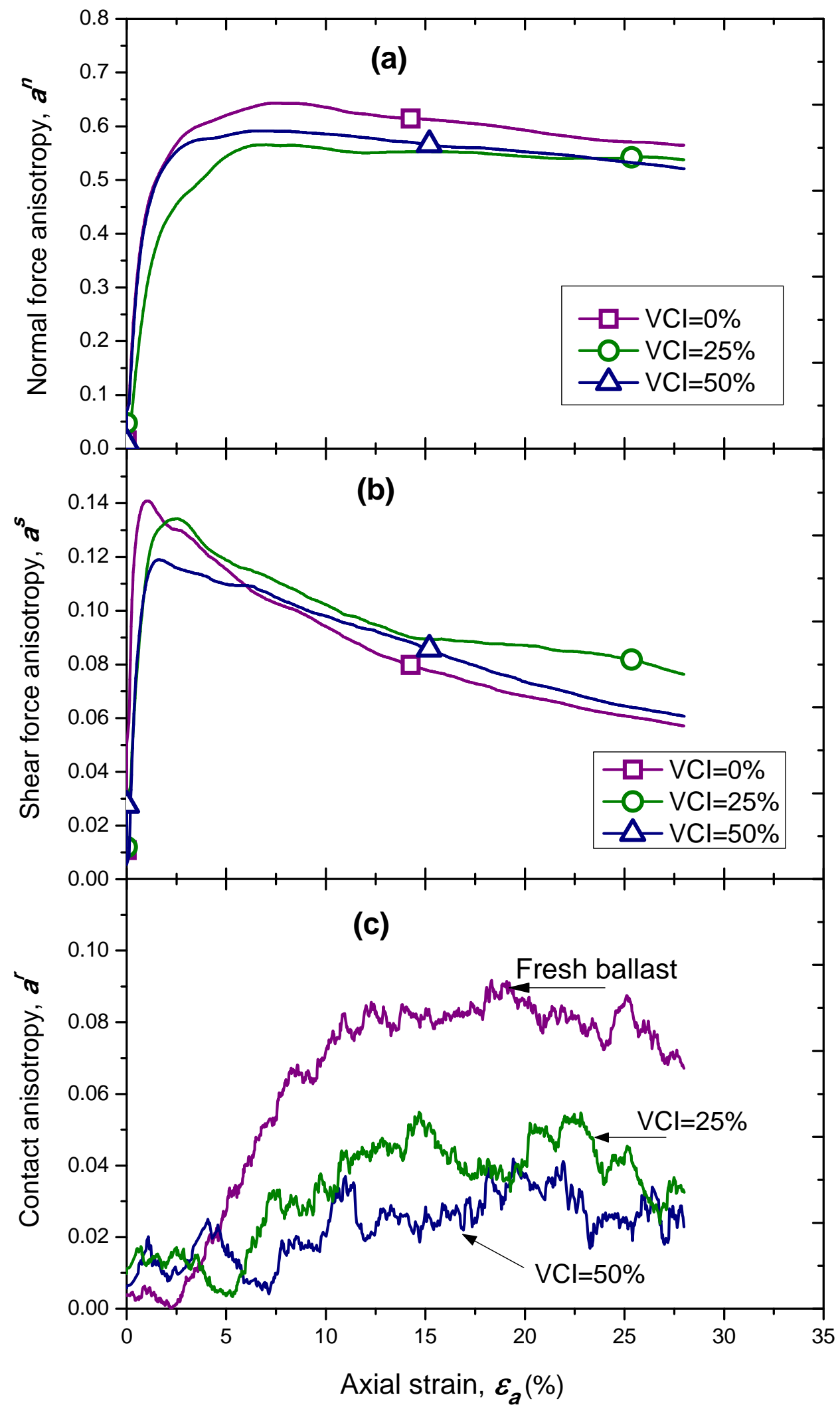

Figure 13. Evolutions of the anisotropy of fresh and fouled ballast at a confining pressure of $30 \mathrm{kPa}$ : (a) anisotropy of normal force, $a^{n}$; (b) anisotropy of shear force, $a^{s}$; (c) anisotropy of normal contact, $a^{r}$. 